\title{
The Effects of Infrared-Blocking Pigments and Deck Venting on Stone-Coated Metal Residential Roofs
}

\author{
William A. Miller
}

January 2006

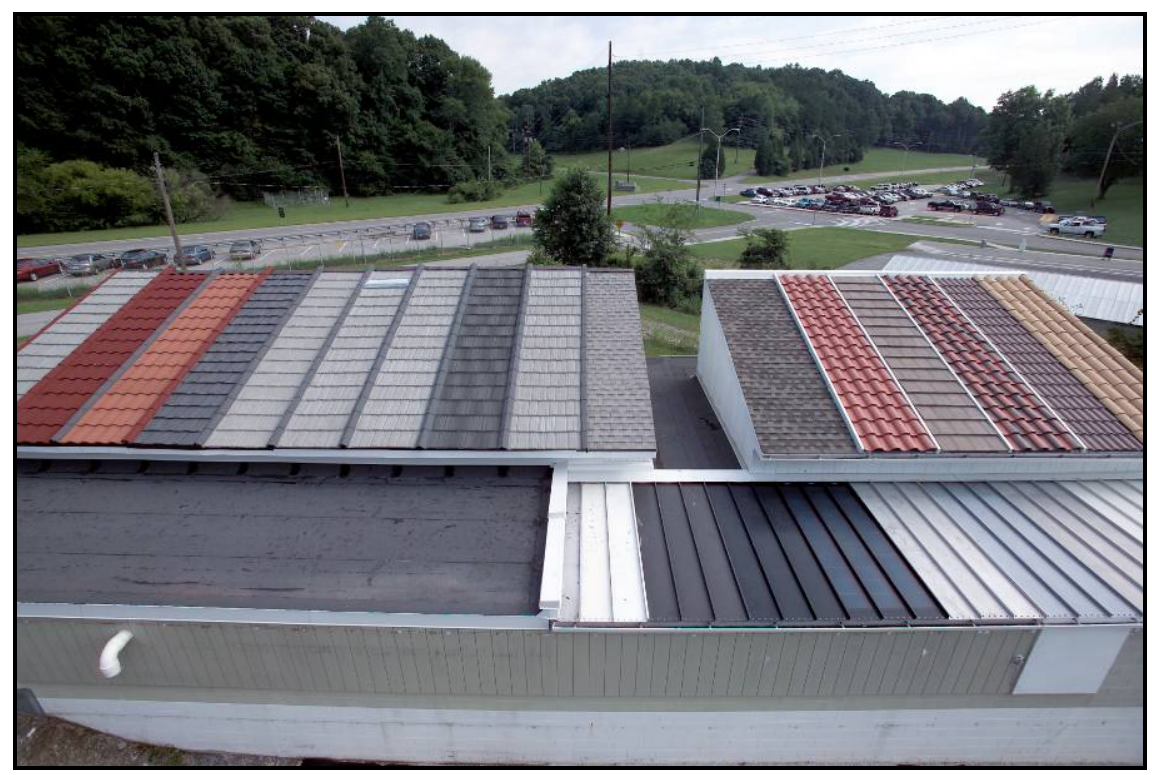




\title{
DOCUMENT AVAILABILITY
}

Reports produced after January 1, 1996, are generally available free via the U.S. Department of Energy (DOE) Information Bridge:

Web site: http://www.osti.gov/bridge

Reports produced before January 1, 1996, may be purchased by members of the public from the following source:

\author{
National Technical Information Service \\ 5285 Port Royal Road \\ Springfield, VA 22161 \\ Telephone: 703-605-6000 (1-800-553-6847) \\ TDD: $703-487-4639$ \\ Fax: 703-605-6900 \\ E-mail: info@ntis.fedworld.gov \\ Web site: http://www.ntis.gov/support/ordernowabout.htm
}

Reports are available to DOE employees, DOE contractors, Energy Technology Data Exchange (ETDE) representatives, and International Nuclear Information System (INIS) representatives from the following source:

Office of Scientific and Technical Information

P.O. Box 62

Oak Ridge, TN 37831

Telephone: 865-576-8401

Fax: 865-576-5728

E-mail: reports@adonis.osti.gov

Web site: http://www.osti.gov/contact.html

This report was prepared as an account of work sponsored by an agency of the United States government. Neither the United States government nor any agency thereof, nor any of their employees, makes any warranty, express or implied, or assumes any legal liability or responsibility for the accuracy, completeness, or usefulness of any information, apparatus, product, or process disclosed, or represents that its use would not infringe privately owned rights. Reference herein to any specific commercial product, process, or service by trade name, trademark, manufacturer, or otherwise, does not necessarily constitute or imply its endorsement, recommendation, or favoring by the United States government or any agency thereof. The views and opinions of authors expressed herein do not necessarily state or reflect those of the United States government or any agency thereof. 


\title{
The Effects of Infrared-Blocking Pigments and Deck Venting on Stone-Coated Metal Residential Roofs
}

\author{
William A. Miller, Ph.D. \\ Building Envelopes Program \\ Oak Ridge National Laboratory
}

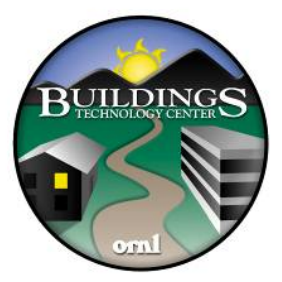

January 2006

\author{
Prepared for the \\ U.S. Department of Energy Buildings Technology Program \\ Marc LaFrance, Program Manager \\ and the \\ Metal Construction Association
}

\author{
Prepared by \\ OAK RIDGE NATIONAL LABORATORY \\ P.O. Box 2008 \\ Oak Ridge, Tennessee 37831-6283 \\ managed by \\ UT-Battelle, LLC \\ for the \\ U.S. DEPARTMENT OF ENERGY \\ under contract DE-AC05-00OR22725
}





\section{CONTENTS}

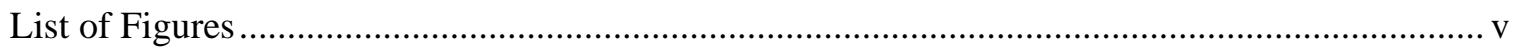

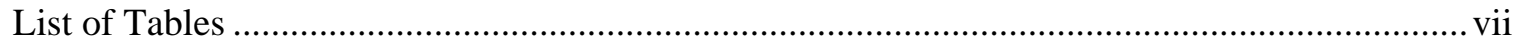

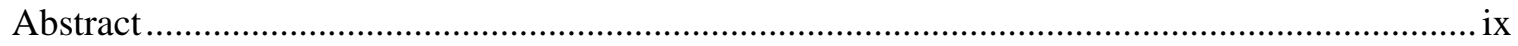

Acknowledgments ...................................................................................................................

Abbreviations, Nomenclature, and Subscripts .............................................................................ii

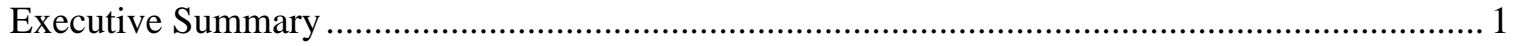

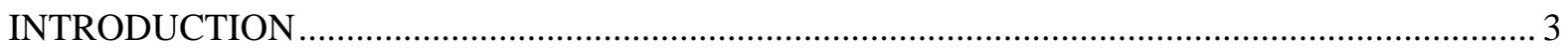

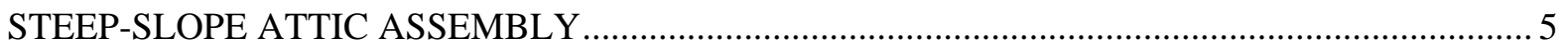

Configuration of Stone-Coated Metal Shakes, Tile, and Painted Metal Roofs................................ 5

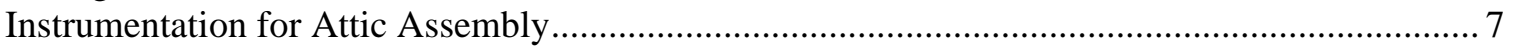

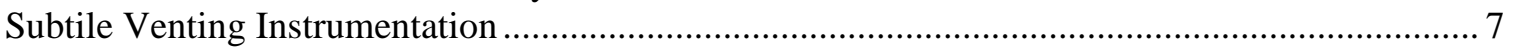

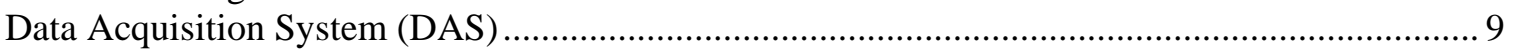

Solar Reflectance and Thermal Emittance Instruments ............................................................ 9

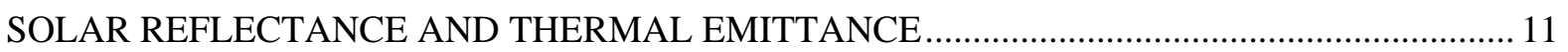

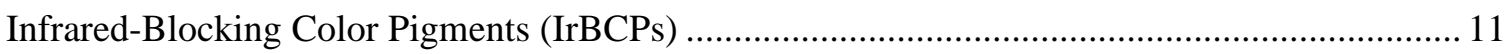

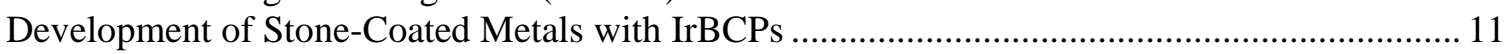

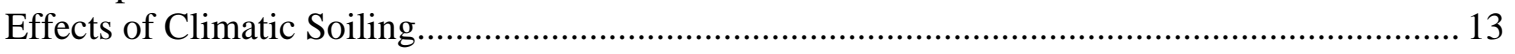

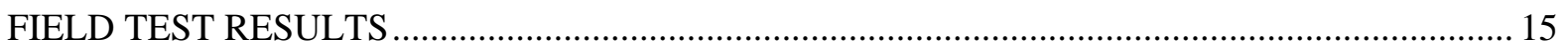

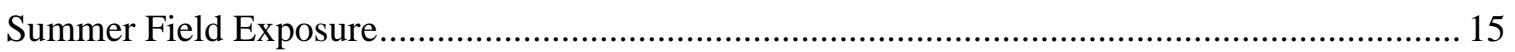

Effect of Underside Venting (Solar Reflectance and Thermal Emittance Fixed) ................ 18

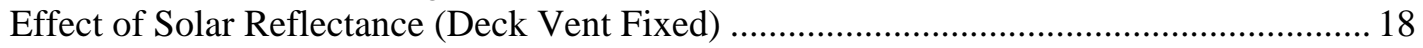

Effect of Thermal Emittance on Roof's Underside (Deck Vent Fixed)................................ 20

Effect of a Fascia Vent (Deck Vent Fixed) .............................................................................. 21

Effect of Direct-to-Deck vs Batten and Counter-Batten ................................................... 21

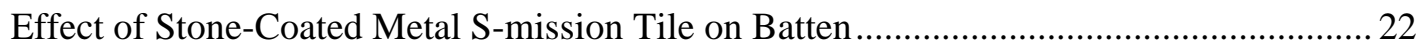

Stone-Coated Metal Shake Retrofit over Existing Cedar Shake Roof................................ 22

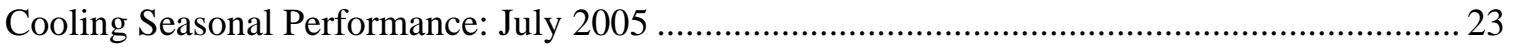

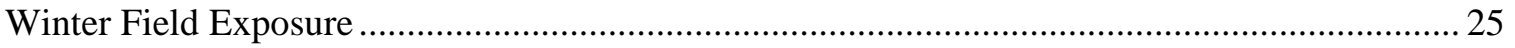

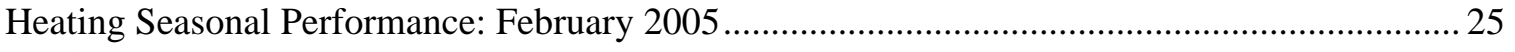

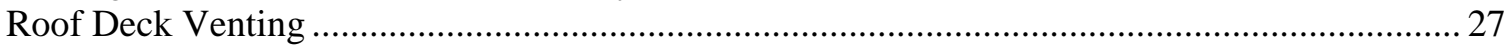

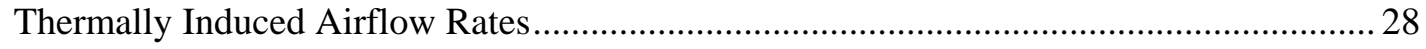

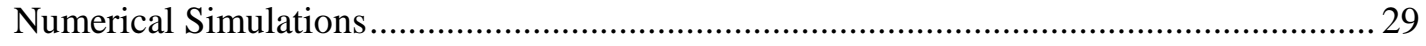

Airflow Measurements Using Tracer Gas Techniques ....................................................... 30

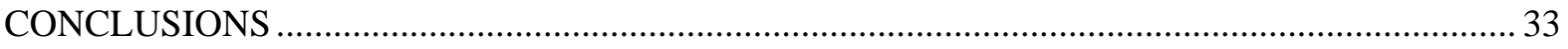

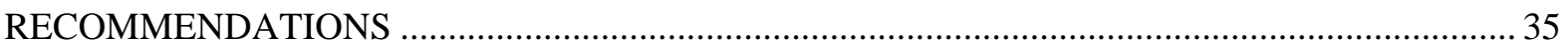

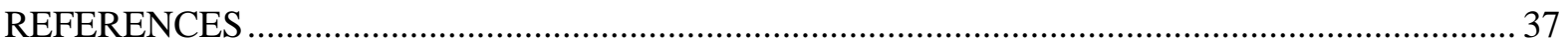





\section{LIST OF FIGURES}

1 The composition of a commercially available stone-coated metal roof product......................... 3

2 The envelope systems research apparatus (ESRA) is a one-story building for testing low- and steep-slope roof products.

3 Two south-facing assemblies of steep-slope attics were placed atop ESRA, and stone-coated metal shakes, S-mission tile, and painted metal shakes were installed by MCA.

4 Construction of the roof deck showing battens and counter-battens for attaching the slate tile and the parapets used to prevent cross flow form one test roof to another.

5 Location of temperature, relative humidity, and heat flow instruments used on each attic assembly

6 Heat flux transducer embedded in the roof deck to measure heat flow penetrating stone-coated metal shake and attic.

7 Setup of attic assembly showing construction materials, instrumentation, and polyisocyanurate insulation used to isolate the attic from adjacent attics.

8 Instrumentation used on underside of light-gray stone-coated metal shake roof with IrBCPs for validating heat transfer correlations predicting the heat transfer driven by thermally induced airflows.

9 A two-coat paint process can use existing infrastructure to manufacture infrared reflective granules for stone-coated metals and asphalt shingles.

10 Effect of IrBCPs and an acrylic overglaze on the solar reflectance of stone-coated metal coupons tested by ORNL and Metro Roof Products.

11 Solar reflectance for stone-coated metals and painted metal roofs exposed to the weather of East Tennessee.

12 Surface temperatures (a) and attic air temperatures (b) for the stone-coated metal roofs and the asphalt shingle control as measured between July 29 and August 5, 2005................... 16

13 Heat penetration through the ceiling of tested attic assemblies with ridge vent open. ................ 17

14 Effect of solar reflectance for two stone-coated shake roofs on battens and counter-battens and effect of underside venting for a stone-coated metal roof

15 Effect of thermal emittance on the underside of two stone-coated metal roofs ......................... 20

16 Effect of direct-nailing a stone-coated metal shake and a PVDF metal shake.......................... 21

17 Effect on heat transfer of retrofit application of stone-coated metal shakes over existing cedar shake roof.

18 Integrated heat flow measured through the roof deck for all tile and shingle roofs during July 2005.

19 Heat flow measured through the roof deck for stone-coated metal shake and shingle roofs during January 2005.

20 Integrated heat flow measured through the roof deck for all stone-coated shake and shingle roofs during February 2005. 
21 Heat transfer phenomena on the underside of an offset-mounted roof...................................... 27

22 Numerical simulations for channel flow with and without battens fastened to the underside of the tile 


\section{LIST OF TABLES}

1 Stone-coated metal roofs placed on ESRA's steep-slope attic assembly .................................. 6

2 Roof deck and attic floor heat flows (Btu/ $\left.\mathrm{ft}^{2}\right)$ integrated over the daylight hours for a

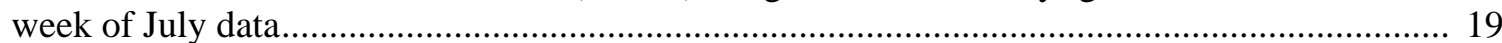

3 Effect of thermal emittance on the underside of a stone-coated metal roof ................................ 20

4 Heat flow in direct-to-deck attachment of stone-coated and painted metal roofs $\left(\mathrm{Btu} / \mathrm{ft}^{2}\right) \ldots \ldots \ldots . . .22$

5 The effect on heat flow of shake and S-mission profile on stone-coated metal roofs................. 22

6 The effect on heat flow of retrofit of light-gray stone-coated metal shakes over

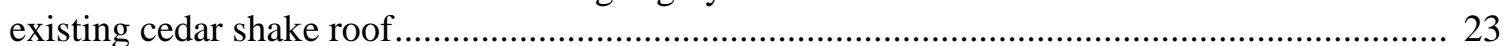

7 Airflow rate and bulk velocity measured under the stone-coated metal shake and S-mission roofs using tracer gas techniques ............................................................................ 31

8 July 2005 cumulative heat flows through the roof deck and floor of the attic assemblies........... 33

9 February 2005 cumulative heat flows through the roof deck and ceiling of the attic assemblies 



\begin{abstract}
Field data show that stone-coated metal shakes and S-mission tile, which exploit the use of infraredblocking color pigments (IrBCPs), along with underside venting reduce the heat flow penetrating the conditioned space of a residence by $70 \%$ compared with the amount of heat flow penetrating roofs with conventional asphalt shingles. Stone-coated metal roof products are typically placed on battens and counter-battens and nailed through the battens to the roof deck. The design provides venting on the underside of the metal roof that reduces the heat flow penetrating a home. The Metal Construction Association (MCA) and its affiliate members installed stone-coated metal roofs with shake and S-mission tile profiles and a painted metal shake roof on a fully instrumented attic test assembly at Oak Ridge National Laboratory (ORNL). Measurements of roof, deck, attic, and ceiling temperatures; heat flows; solar reflectance; thermal emittance; and ambient weather were recorded for each of the test roofs and also for an adjacent attic cavity covered with a conventional pigmented and directnailed asphalt shingle roof. All attic assemblies had ridge and soffit venting; the ridge was open to the underside of the stone-coated metal roofs. A control assembly with a conventional asphalt shingle roof was used for comparing deck and ceiling heat transfer rates.
\end{abstract}





\section{ACKNOWLEDGMENTS}

Funding for this project was provided by the U.S. Department of Energy under the direction of Marc LaFrance of the Building Technologies Program. The IrBCP project team members are André Desjarlais, William Miller, and Tom Petrie, all of ORNL's Buildings Technology Center. Numerical simulations were produced by Dr. Majid Keyhani of the University of Tennessee, Knoxville. The Metal Construction Association and its affiliate members provided the stone-coated shake and S-mission roofs. Metro Roof Products constructed the attic assemblies and provided valuble assistance in installing the roofs on the steep-slope assemblies. The financial support of the Metal Construction Association and the guidance of Metro Roof Products is greatly appreciated. 



\section{ABBREVIATIONS, NOMENCLATURE, AND SUBSCRIPTS}

$\begin{array}{ll}\text { Abbreviations } & \\ \text { ASTM } & \text { American Society for Testing and Materials } \\ \text { BTC } & \text { Buildings Technology Center (ORNL) } \\ \text { CMRC } & \text { Cool Metal Roofing Coalition } \\ \text { DAS } & \text { data acquisition system } \\ \text { DOE } & \text { U.S. Department of Energy } \\ \text { ESRA } & \text { envelope systems research apparatus } \\ \text { HFT } & \text { heat flux transducer } \\ \text { IrBCP } & \text { infrared-blocking color pigment } \\ \text { LBNL } & \text { Lawrence Berkeley National Laboratory } \\ \text { MCA } & \text { Metal Construction Association } \\ \text { ORNL } & \text { Oak Ridge National Laboratory } \\ \text { OSB } & \text { oriented strand board } \\ \text { PVDF } & \text { polyvinylidene fluoride } \\ \text { SBS } & \text { styrene butadiene styrene } \\ \text { TiO } & \text { titanium dioxide }\end{array}$

\section{Nomenclature}

\begin{tabular}{|c|c|c|c|}
\hline$\delta_{\mathrm{t}}$ & thermal boundary layer thickness (ft) & $\mathrm{P}$ & wetted perimeter of channel (ft) \\
\hline$\varepsilon$ or TE & thermal emittance & $\dot{\mathrm{m}}$ & mass flow rate $(\mathrm{lbm} / \mathrm{hr})$ \\
\hline$\rho$ or SR & solar reflectance & $\mathrm{C}_{\mathrm{P}}$ & specific heat $(\mathrm{Btu} / \mathrm{lbm} \cdot \mathrm{R})$ \\
\hline $\mathrm{L}$ & length from soffit to roof ridge ( $\mathrm{ft}$ ) & $\alpha$ & thermal diffusivity $\left(\mathrm{ft}^{2} / \mathrm{s}\right)$ \\
\hline $\mathrm{H}$ & underside height of air gap & CDD & $\begin{array}{l}\text { cooling degree days based on } \\
65^{\circ} \mathrm{F}\end{array}$ \\
\hline $\mathrm{T}$ & temperature $\left({ }^{\circ} \mathrm{F}\right)$ & HDD & $\begin{array}{l}\text { heating degree days based on } \\
65^{\circ} \mathrm{F}\end{array}$ \\
\hline$\hbar$ & convective coefficient $\left(\mathrm{Btu} / \mathrm{hr} \cdot \mathrm{ft}^{2}{ }^{\circ} \mathrm{F}\right)$ & $\theta$ & roof slope \\
\hline C & concentration of $\mathrm{CO}_{2}$ (ppmv) & $v$ & kinematic viscosity ( $\left.\mathrm{ft}^{2} / \mathrm{s}\right)$ \\
\hline V & volume of inclined channel & $\mathrm{k}$ & $\begin{array}{l}\text { thermal conductivity } \\
\left(\mathrm{Btu} / \mathrm{hr} \cdot \mathrm{ft} \cdot{ }^{\circ} \mathrm{F}\right)\end{array}$ \\
\hline$\dot{V}$ & volumetric flow rate (cfm) & $\eta$ & $=\mathrm{y} / \delta_{\mathrm{t}}$ \\
\hline$\beta$ & coefficient of thermal expansion $\left(1 /{ }^{\circ} \mathrm{F}\right)$ & $\mathrm{U}(\mathrm{x}, \mathrm{y})$ & velocity (ft/sec) \\
\hline g & gravity $\left(32.2\right.$ ft/s $\left.{ }^{2}\right)$ & $\operatorname{Pr}$ & Prandtl number $(=v / \alpha)$ \\
\hline$q^{\prime \prime}$ & heat flux $\left(\mathrm{Btu} / \mathrm{hr} \cdot \mathrm{ft}^{2}\right)$ & Ra & Rayleigh number $=\left(\frac{g \beta(\Delta T) L^{3}}{v \cdot \alpha}\right)$ \\
\hline Ra* & modified Rayleigh number $=\left(\frac{g \beta q^{\prime \prime} L^{4}}{k \cdot v \cdot \alpha}\right)$ & & \\
\hline
\end{tabular}




\section{Subscripts}

$\begin{array}{ll}\text { air } & \text { air within inclined channel } \\ \text { air in } & \text { air leaving ridge } \\ \text { air out } & \text { air entering soffit } \\ \text { channel } & \text { inclined air gap made by tile and roof deck } \\ \text { H } & \text { underside height of air gap } \\ \text { i } & \text { initial value } \\ \text { IR } & \text { infrared spectrum } \\ \text { roof } & \text { tile roof surface or underside } \\ \text { solar } & \text { irradiance } \\ \text { t } & \text { time } \\ \text { wall } & \text { underside of tile roof } \\ \text { x } & \text { x-distance from soffit to ridge } \\ y & \text { y-distance normal to roof deck } \\ \infty & \text { outdoor ambient }\end{array}$




\section{EXECUTIVE SUMMARY}

An assembly of steep-slope attics with shed-type roofs was installed on top of the envelope systems research apparatus (ESRA) at Oak Ridge National Laboratory (ORNL) for field-testing stone-coated metal roofs with shake and S-mission profiles. All roofs were equipped with ridge and soffit vents for ventilating the attic. The ratio of the vent opening area to attic floor area was 1 to 300. The stonecoated metal roofs were either directly nailed to the roof deck or offset-mounted from the deck using battens and counter-battens. The offset mounting provided a ventilation path along the underside of the shake and S-mission roof profiles.

The objective of this project was to document the potential energy savings of stone-coated metal roofs with and without IrBCPs and also the benefits of venting between the underside of the roof cover and the roof deck. The Metal Construction Association (MCA) and its affiliate members are keenly interested in specifying their roofs as cool roof products and want to know the effects of solar reflectance, thermal emittance and underside venting.

Dark-gray and light-gray stone-coated metal shakes with and without infrared-blocking color pigments (IrBCPs), a steel gray polyvinylidene fluoride (PVDF) painted metal shake with IrBCPs, and two stone-coated metal roofs with a S-mission profiles were installed on the attic assemblies by MCA. The facility enabled a direct side-by-side comparison of the effect of IrBCPs, fascia and deck venting, underside thermal emittance roof profile (whether moderately flat or S-mission), and a retrofit application over an existing cedar shake roof. To compare deck and ceiling heat transfer rates, a control assembly with a conventional asphalt shingle roof was set up.

Solar reflectance measures of the stone-coated metal and painted metal roofs exposed at ORNL were collected quarterly. The light-gray shakes had an initial solar reflectance of about 0.25 and an initial thermal emittance of 0.90 . The underside of the shakes is bare metal with a thermal emittance of 0.34 , which acts as a radiant barrier for the roof structure. After almost $1 \frac{1}{2}$ years of exposure, the light-gray shakes showed about a $10 \%$ loss in solar reflectance, which is leveling off as the time of exposure approaches 2 years. The dark-gray shake actually showed a slight increase in solar reflectance due to the accumulation of airborne contaminants. Dust tends to lighten a darker color. The painted metal roof with IrBCPs had the highest solar reflectance of the roofs tested, about 0.29. Also, it lost only about 3.5\% of its original solar reflectance because of its durable PVDF paint finish.

Stone-coated metal roofs are energy-efficient, offering excellent energy credits as steep-slope cool roof products because of the improved solar reflectance afforded by IrBCPs and the underside venting. The best-performing roofs were the S-mission profile roofs on battens and the light-gray IrBCPs shake roof on battens and counter-battens. The reduction in heat penetrating the ceiling with these prototypes was about $70 \%$ of the daily heat penetrating the control shingle roof. Thus, the home air-conditioner would handle only 30\% of the load incurred by a home with asphalt shingle roof, resulting in an energy savings cost of about $7 \nsubseteq$ per square foot per year. Retrofitting a stone-coated shake roof over an existing cedar shake roof proved to be beneficial and resulted in the best thermally performing roof system, dropping ceiling heat flow by $75 \%$ that of an attic with a conventional shingle roof.

The stone-coated metal roofs negate the heating penalty associated with a cool roof in Tennessee's moderate climate. ${ }^{1}$ The improved summer performance coupled with the reduced heat losses during the winter as compared to a shingle roof show that offset-mounting stone-coated metal roofs can provide the metal roof industry the opportunity to market stone-coated metal roofs in climates that are

\footnotetext{
${ }^{1}$ Tennessee has 3662 heating degree days based on $65^{\circ} \mathrm{F}\left(\mathrm{HDD}_{65}\right)$ and 1366 cooling degree days based on $65^{\circ} \mathrm{F}$ $\left(\mathrm{CDD}_{65}\right)$.
} 
predominated more by heating loads. Typically, the monetary breakeven point for cool roofs occurs where the ratio (CDD/HDD) 65 is about 0.4; however, underside venting can move this climatic boundary of affordable energy cost savings farther north.

Numerical simulations of the air flow in the inclined air channel formed by stone-coated metal roof systems demonstrated that naturally induced flow can be expected at very low roof slopes and very small temperature differences, well below those experienced in conventional roofing systems. Natural convection flow inside inclined ducts is conduction-dominated if the Rayleigh number $\left(\mathrm{Ra}_{\mathrm{H}}\right)^{2}$ is less than about $1708 / \cos (\theta)$. Simulations yielded a bulk airflow rate on the underside of the roofs that was very similar to measures made using tracer gas techniques.

The AtticSim computer tool was validated against the steep-slope attic assembly with direct-nailed asphalt shingles. The model predicted the surface temperature of the shingles, the attic air temperature, and, as a result, the heat flow penetrating the conditioned space. Efforts are continuing to modify the code for predicting the effects of the airflow occurring on the underside of the stonecoated metal roofs. Correlations by McAdams (1954) and Brinkworth (2000) and simple boundary layer theory for a constant solar flux are predicting reasonable heat transfer measures within the inclined air channel. The measures of airflow determined from the tracer gas experiments match well the back-calculated values deduced from the McAdams (1954), Brinkworth (2000) and simple boundary layer theory correlations. We therefore have good representative airflow measures for subtile venting and are in good position to implement an algorithm formulated after the work by Brinkworth (2000) for use in AtticSim to predict the thermal performance of roofs with subtile venting.

\footnotetext{
${ }^{2}$ The height of the air gap is the characteristic length of the Rayleigh number $\left(\operatorname{Ra}_{H}\right)$ used here.
} 


\section{INTRODUCTION}

A new generation of roofing products is being introduced to the market to bring relief to homeowners and utilities alike. The addition of cool color pigments to paints is reducing the amount of energy needed to cool buildings, which in turn helps power companies reduce hot-weather energy consumption. Cool color pigments will also positively impact the environment by helping reduce carbon dioxide emissions, metropolitan heat buildups, and urban smog.

Industry researchers, including those working with the U.S. Department of Defense, developed the first prototype cool color pigments for military camouflage to match the visible and the near-infrared reflectance of background foliage. The high infrared reflectance of these pigments, which blocks the penetration of near-infrared radiation into the paint, can be exploited to manufacture roofing materials that reflect more sunlight than do conventionally pigmented roofing products.

The U.S. Department of Energy's (DOE’s) Buildings Technologies Program provided funding for the Building Envelope Program at Oak Ridge National Laboratory (ORNL) to assess the benefits of infrared-blocking color pigments (IrBCPs) for the thermal performance of granular stone-coated metal roofs. DOE funded the work because of (1) the durability of stone-coated metal roofs (which are manufacturer-warranted for 50 years); (2) the potential benefit in cooling energy savings to be achieved by exploiting the use of IrBCPs; and (3) the potential energy benefits derived from venting the roof deck.

To examine the effects of cool color pigments, a steep-slope roof assembly was constructed for field testing and documenting the energy savings and durability of roof products exploiting the use of IrBCPs. The metal roofing manufacturers and pigment (colorant) manufacturers selected appropriate IrBCPs; applied them to stone-coated metal shakes, S-mission tile, and painted metal roof products; and field-tested the prototypes on a steep-slope roof assembly located at the ORNL Buildings Technology Center (BTC).

The BTC completed one year of field testing stone-coated shakes and S-mission tile and is reporting the results for completion of the DOE Milestone Task D8.

The stone-coated metal product has a multiplicity of profiles but was tested using S-mission tile and shake profiles. The base metal is made of 26-gauge Zincalume "Plus," a pre-primed galvanized steel that is coated with a layer of stone chips (Fig. 1). An acrylic base coat and an overglaze are applied to seal the product. Parker, Sonne, and Sherwin (2002) demonstrated that a Florida home with a "white reflective" barrel-shaped concrete tile roof used $22 \%$ less cooling energy annually than an identical

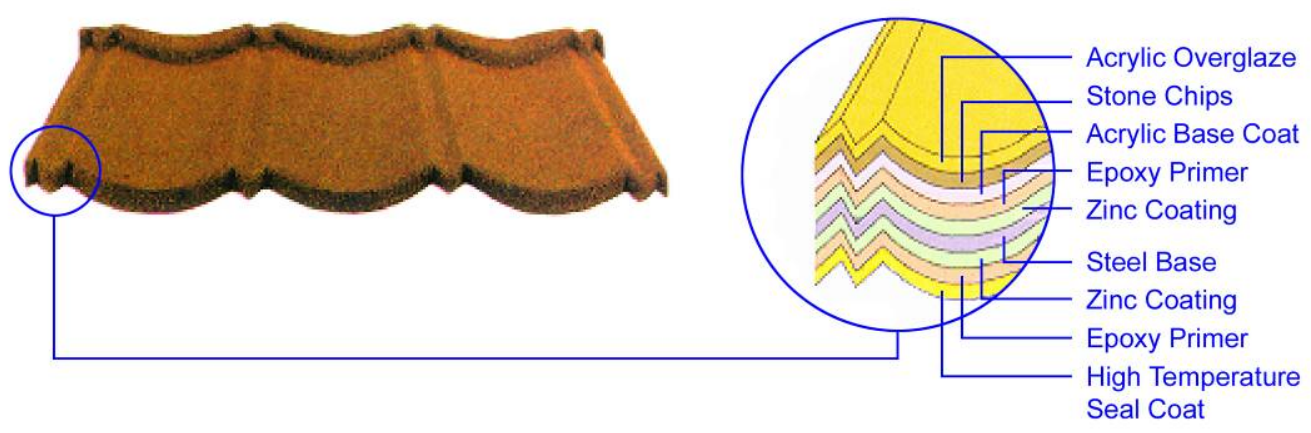

Fig. 1. The composition of a commercially available stone-coated metal roof product. 
adjacent home with a dark absorptive asphalt shingle roof. The cost savings due to the reduced use of comfort cooling energy was about $\$ 120$, or about $6.7 \$$ per square foot per year.

The venting of the underside of a roof cover also provides thermal benefits for comfort cooling. Residential roof tests by Beal and Chandra (1995) demonstrated a 45\% reduction in the daytime heat flux penetrating a counter-batten tile roof as compared to a direct-nailed shingle roof. Parker, Sonne, and Sherwin (2002) observed in their study that a barrel-shaped terra-cotta tile with moderate solar reflectance reduced the home's annual cooling load by about $8 \%$ of the base load measured for an identical adjacent home with an asphalt shingle roof. These reported energy savings are in part attributed to a thermally driven airflow within the air channel formed by the underside of the tile and the roof deck. The airflow is driven by buoyancy and/or wind forces. The air channel also provides an improvement in the insulating effect of the roofing system. The heat transfer can switch from conduction to single-cell convection to Bénard cell convection depending on the aspect ratio made by the underside of the tile and the roof deck, the slope of the roof, and the weather. The coexistence and competition between the various modes of heat transfer requires experimental measurements and numerical simulations to model and accurately predict the heat flows observed for subtile venting. Therefore, a combined experimental and analytical approach was conducted, with one year of field data collected that included summer and winter exposure of the stone-coated metal products. 


\section{STEEP-SLOPE ATTIC ASSEMBLY}

The BTC's envelope systems research apparatus (ESRA) is a one-story building used to expose large areas of low-slope and steep-slope roofs in East Tennessee's climate. Two sides of the building are mostly below grade, while the other two sides are mostly above grade (Fig. 2). The interior of ESRA is heated and cooled to a constant temperature of $70^{\circ} \mathrm{F}$ year-round. The long axis of the building is oriented east-west, and test roofs are oriented facing south to receive full solar exposure. Nine attic assemblies, each $4 \mathrm{ft}$ wide and $16 \mathrm{ft}$ long, were built and installed adjacent to an existing steep-slope attic assembly that was used for field-testing clay and concrete tile roofs (Fig. 3). Metro Roof Products prefabricated the attic assemblies at its facility and shipped them to ORNL for placement on ESRA. Each attic assembly contains 6 in. of polyisocyanurate insulation on both interior gable sides and $4 \mathrm{in}$. of insulation on the rear wall. A styrene-butadiene-styrene (SBS)-modified coated base sheet was used as the underlayment on the 0.625 -in. oriented strand board (OSB) roof deck.

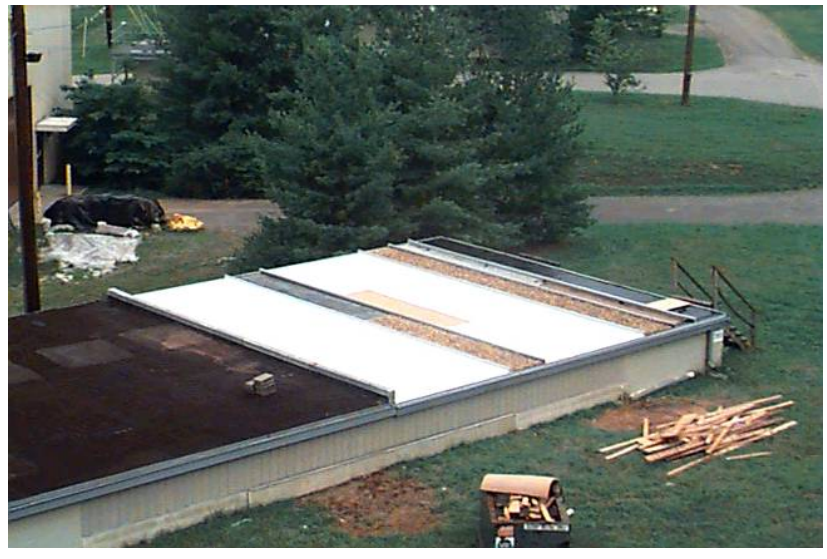

Fig. 2. The envelope systems research apparatus (ESRA) is a one-story building for testing low- and steep-slope roof products.

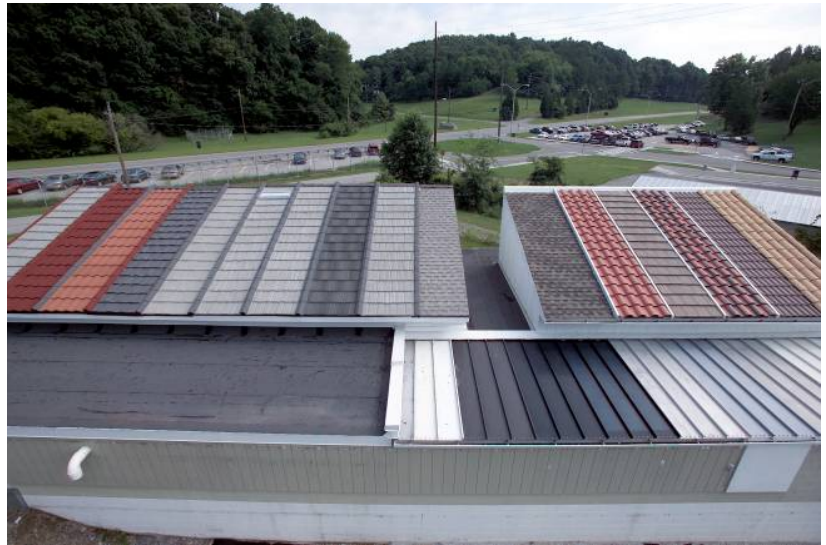

Fig. 3. Two south-facing assemblies of steep-slope attics were placed atop ESRA, and stone-coated metal shakes, S-mission tile, and painted metal shakes were installed by MCA.

\section{Configuration of Stone-Coated Metal Shakes, Tile, and Painted Metal Roofs}

Metro Roof Products and DuraLoc, on behalf of MCA and the Cool Metal Roofing Coalition (CMRC), selected light-gray and dark-gray stone-coated metal shakes for testing at ORNL. A painted metal shake with a PVDF base coat and two S-mission stone-coated metal profiles were also included in the matrix of test roofs. A conventional asphalt shingle, the painted metal shake, and one stonecoated metal shake were nailed directly to the deck. Two stone-coated tile facsimile metal roofs were installed with $2 \times 2$ in. battens. All other roofs were installed on a batten and counter-batten system (Table 1). Here, $1 \times 4$ in. counter-battens are nailed to the roof deck from soffit to ridge, and $2 \times 2$ in. battens are placed above the counter-battens and nailed to the deck (Fig. 4). The battens run parallel to the ridge. Venting occurs up along the underside of the stone-coated metal roofs because of the design of the tile profile and because of the construction of the roof deck. The batten and batten with counter-batten installations provide a unique inclined air channel running from the soffit to the ridge. The bottom surface of the air channel is formed by the roof deck and 30\# felt paper and is relatively smooth and in plane with the roof deck. The top surface is created by the underside of the stone- 
coated metal and is broken at regular intervals by the batten ${ }^{3}$ wood furring strip (into which the shakes are fastened). For batten and counter-batten construction, the counter-battens are fastened to the roof deck and run from soffit to ridge, and the battens are nailed on top of the counter-battens (Fig. 4).

ORNL selected a commercially available asphalt shingle with a solar reflectance of 0.093 and a thermal emittance of 0.89 as the control for comparing the thermal performance of the metal products (shown in lane 6 from the right in Fig. 3). Each test roof has its own attic cavity with 5 in. of expanded polystyrene insulation installed between adjacent cavities. This reduces the heat leakage between cavities so that each attic assembly and test roof can be tested as a stand-alone assembly.

Table 1. Stone-coated metal roofs placed on ESRA's steep-slope attic assembly

\begin{tabular}{|c|c|c|c|c|c|c|}
\hline Profile & Color & Pigment & Surface & Underside & Attachment & $\begin{array}{l}\text { Subtile } \\
\text { venting }^{a}\end{array}$ \\
\hline \multicolumn{7}{|c|}{ Lane 7: Control asphalt shingle (SR09E89) } \\
\hline Shingle $^{b}$ & Dark-gray & Conventional & Aggregate & NA & Direct-to-deck & No \\
\hline \multicolumn{7}{|c|}{ Lane 8: Shk-LG-IRRagg-Upt-CB (SR246E90) } \\
\hline Shake & Light-gray & IrBCP & Aggregate & Unpainted & $\begin{array}{l}\text { Batten and } \\
\text { counter- } \\
\text { batten }^{c}\end{array}$ & Yes \\
\hline \multicolumn{7}{|c|}{ Lane 9: Shk-DG-CNVagg-Upt-CB (SR08E90) } \\
\hline Shake & Dark-gray & Conventional & Aggregate & Unpainted & $\begin{array}{l}\text { Batten and } \\
\text { counter-batten }\end{array}$ & Yes \\
\hline \multicolumn{7}{|c|}{ Lane 10: Shk-LG-IRRagg-Pt-CB (SR25E90) } \\
\hline Shake & Light-gray & $\operatorname{IrBCP}$ & Aggregate & Painted & $\begin{array}{l}\text { Batten and } \\
\text { counter-batten }\end{array}$ & Yes \\
\hline \multicolumn{7}{|c|}{ Lane 11: Shk-LG-IRRagg-Upt-CB-Fascia Vent (SR244E90) } \\
\hline Shake & Light-gray & IrBCP & Aggregate & Unpainted & $\begin{array}{l}\text { Batten and } \\
\text { counter-batten }\end{array}$ & Fascia vent \\
\hline \multicolumn{7}{|c|}{ Lane 12: Shk-LG-IRRagg-Upt-DDk (SR25E90) } \\
\hline Shake & Light-gray & IrBCP & Aggregate & Unpainted & Direct to deck & Yes \\
\hline \multicolumn{7}{|c|}{ Lane 13: PVDF Metal-DG-IRRPnt-Upt-DDk (SR287E90) } \\
\hline $\begin{array}{l}\text { Country } \\
\text { Manor } \\
\text { Shake }\end{array}$ & Dark-gray & IrBCP & Painted & Unpainted & Direct to deck & Yes \\
\hline \multicolumn{7}{|c|}{ Lane 14: S-mission-TC-IRRagg-Upt-Batten (SR257E90) } \\
\hline Mission Tile & Terra cotta & $\operatorname{IrBCP}$ & Aggregate & Unpainted & Batten & Yes \\
\hline \multicolumn{7}{|c|}{ Lane 15: S-mission-TC-CNVagg-Upt-Batten (SR15E90) } \\
\hline Mission Tile & Terra cotta & Conventional & Aggregate & Unpainted & Batten & Yes \\
\hline \multicolumn{7}{|c|}{ Lane 16: Shk-LG-IRRagg-Upt-CB over Cedar Shake (SR24E90) } \\
\hline Shake & Light-gray & $\mathrm{IrBCP}$ & Aggregate & Unpainted & $\begin{array}{l}\text { Batten and } \\
\text { counter-batten } \\
\text { on cedar } \\
\text { shake }\end{array}$ & Yes \\
\hline
\end{tabular}

${ }^{a}$ All lanes have soffit and ridge venting. ${ }^{b}$ Boldface indicates baseline conditions. ${ }^{c}$ Battens are $2 \times 2$ in. wood run along roof width. Counter-battens are $1 \times 4$ in. and run from soffit to ridge.

\footnotetext{
${ }^{3}$ Battens are fastened directly to roof deck or fastened on top of a counter-batten.
} 


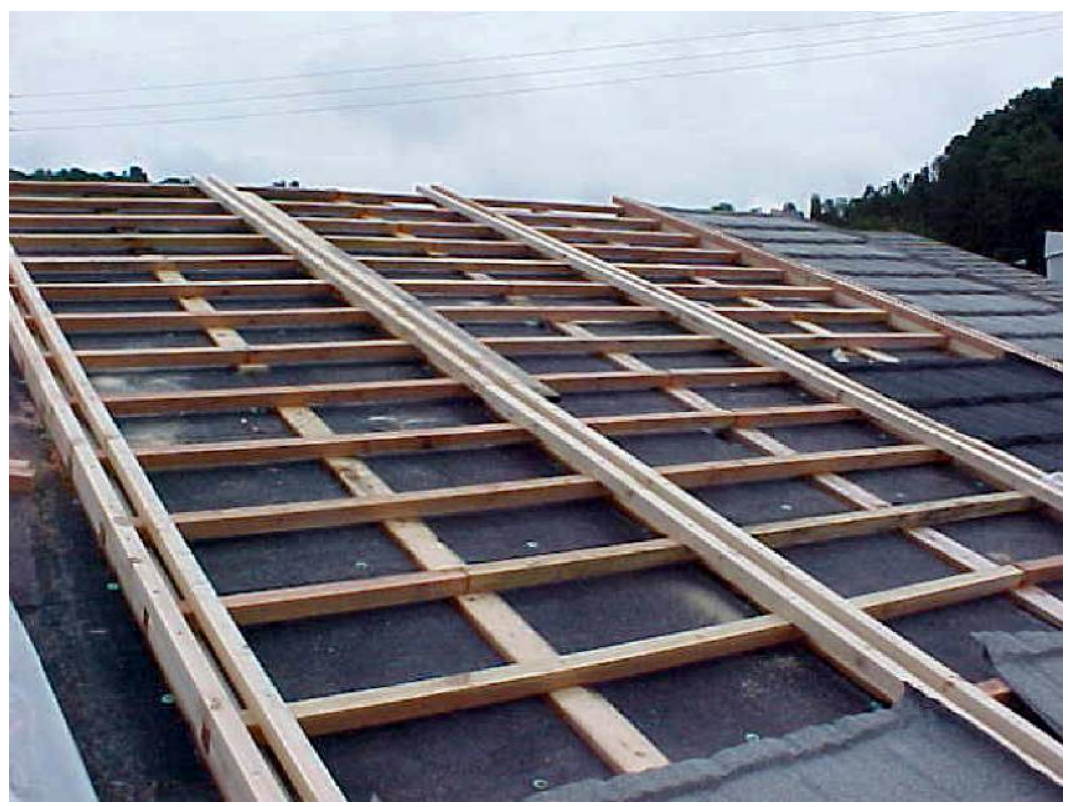

Fig. 4. Construction of the roof deck showing battens and counterbattens for attaching the slate tile and the parapets used to prevent cross flow form one test roof to another.

\section{Instrumentation for Attic Assembly}

The surface and underside temperatures of the stone-coated metal, the temperatures of the roof deck on both sides of the OSB, and the heat flux transmitted through the roof deck are directly measured (Fig. 5) and recorded by a data acquisition system (DAS). All roof decks have a 2-in.-square by 0.18in.-deep routed slot (Fig. 6) with a heat flux transducer (HFT) inserted to measure the heat flow crossing the deck. Each HFT was placed in a guard made of the same OSB material used in construction and was calibrated using a FOX 670 heat flow meter to correct for shunting effects (i.e., distortion due to three-dimensional heat flow). The attic cavities also have an instrumented area in the floor (i.e., ceiling) for measuring the heat flows into the conditioned space. The attic floor consists of a metal deck, a 1-in.-thick piece of wood fiberboard lying on the metal deck, and a $1 / 2$-in.-thick piece of wood fiberboard placed atop the 1-in.-thick piece (Fig. 7). The HFT for measuring ceiling heat flow is embedded between the two pieces of wood fiberboard. It was also calibrated in a guard made of wood fiberboard before being placed in field service.

\section{Subtile Venting Instrumentation}

Stone-coated metal roofs are traditionally offset from the roof deck, and the convection heat transfer in the batten space may be mixed - that is, it may be a combination of forced and natural convection heat transfer. Analytic data on mixed convection phenomena are sparse because buoyancy effects can cause oscillations in the inertia flow field that make convergent numerical solutions difficult to obtain. Therefore, the effect of venting on the underside of the roof, between the roof deck and exterior cool pigmented granules, is a key measurement issue that required additional instrumentation.

The shake and S-mission profile roofs have thermocouples and HFTs at four stations starting at the soffit and spaced apart evenly (about a $\Delta x$ of $4 \mathrm{ft}$ ) up to the ridge to measure the bulk air temperatures and the heat flux near the underside of the metal (Fig. 8). These measurements are used to estimate 


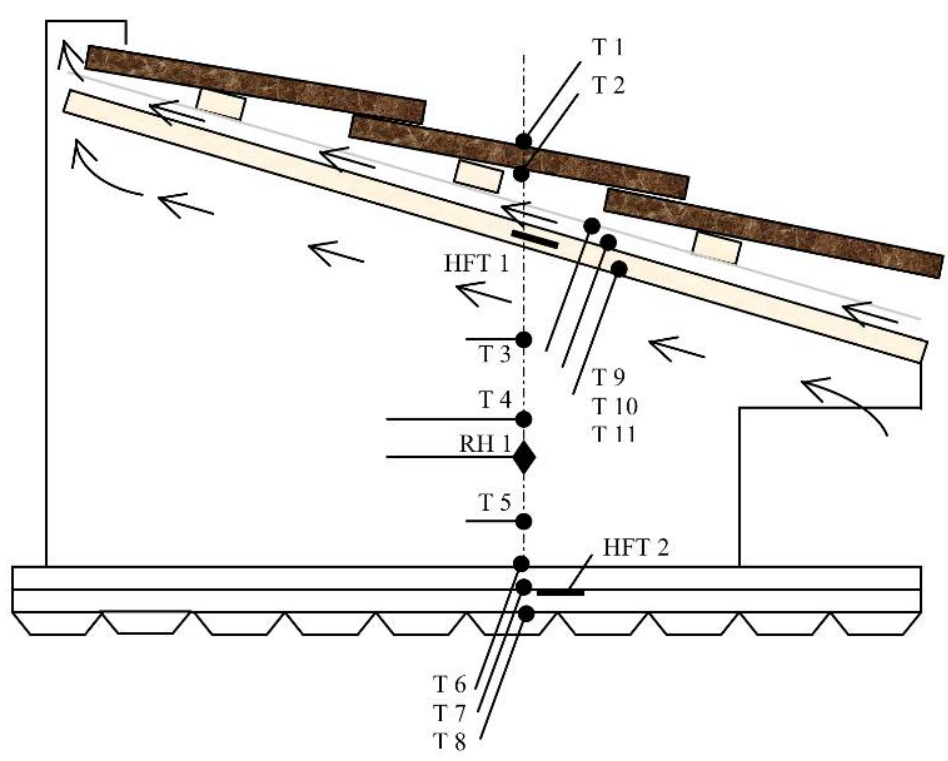

Fig. 5. Location of temperature, relative humidity, and heat flow instruments used on each attic assembly.

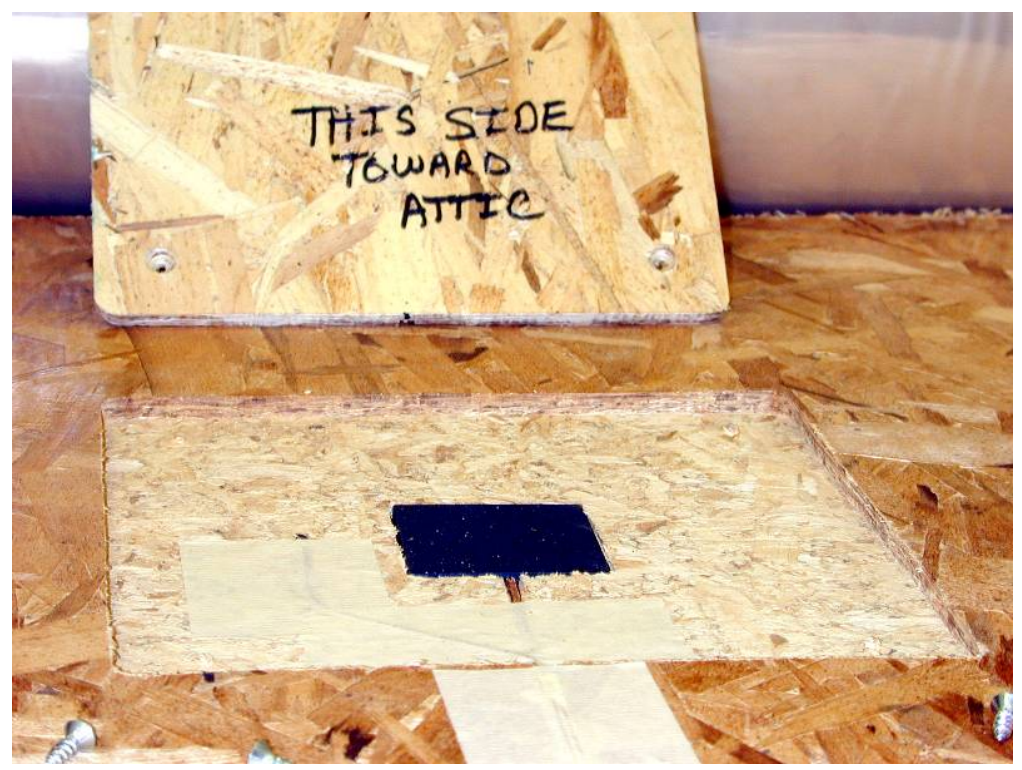

Fig. 6. Heat flux transducer embedded in the roof deck to measure heat flow penetrating stone-coated metal shake and attic.

the convective heat transfer within the air channel made by the underside of the metal roof and the roof deck. On a typical warm, sunny day, the irradiance from the sun will penetrate the stone-coated metal roof and will cause a net inflow of heat into the air channel. A portion of this heat is conducted into the attic space. Heat penetrating the attic from the roof deck as measured by the HFTs is defined as positive heat flow. Heat entering the attic floor or conditioned space from the attic is also defined as positive heat flow. Similarly, heat leaving the attic floor and entering the attic, and heat escaping the roof to the night sky, are considered negative heat flows. 


\section{Data Acquisition System (DAS)}

A 700-MHz Pentium III computer collected field data using FIX DMACS version 7.1 software supported by Windows version 2000. The code scanned all instruments every $15 \mathrm{~s}$ and electronically recorded averages at 15-min. intervals to a historical database within the FIX DMACS hierarchy. Data were retrieved weekly from the historical database and written to a spreadsheet for combination with the weather data and preparation for later data reduction and analysis.

\section{Solar Reflectance and Thermal Emittance Instruments}

A Device \& Services Co. solar spectrum reflectometer was used to measure the solar reflectance (total hemispherical reflectance over the spectrum of the sun's energy) of the roof samples. The device uses a tungsten halogen lamp to diffusely illuminate a sample. Four detectors, each fitted with different filters, measure the reflected light in different wavelength ranges. The four signals are weighted in appropriate proportions to yield the total hemispherical reflectance. The device was proven accurate to within \pm 0.003 units (Petrie et al. 2000) through validation against the ASTM E-903 method (ASTM 1996). However, because the IrBCPs exhibit high infrared reflectance, some of the field samples were also measured at Lawrence Berkeley National Laboratory (LBNL) using a spectrometer to check the portable reflectometer. The average absolute difference between the Device \& Services reflectometer and the spectrometer was about 0.02 points of reflectance, with the spectrometer consistently reading lower than the reflectometer. (For example, the reflectometer measured a solar reflectance of 0.741 for an painted metal with IrBCPs while the spectrometer measured 0.73.)

The impact of emittance on roof temperature is as important as that of reflectance. A portable Device \& Services emissometer was used to measure the thermal emittance using the procedures in ASTM $\mathrm{C}-1371$ (ASTM 1997). The device has a thermopile radiation detector, which is heated to $180^{\circ} \mathrm{F}$. The detector has two high- $\varepsilon$ and two low- $\varepsilon$ elements and is designed to respond only to radiation heat transfer between itself and the sample. Because the device is comparative between the high- $\varepsilon$ and the low- $\varepsilon$ elements, it must be calibrated in situ using two standards, one having an emittance of 0.89 , the other having an emittance of 0.06. Kollie, Weaver, and McElroy (1990) verified the instrument's precision as \pm 0.008 units and its accuracy as \pm 0.014 units in controlled laboratory conditions.

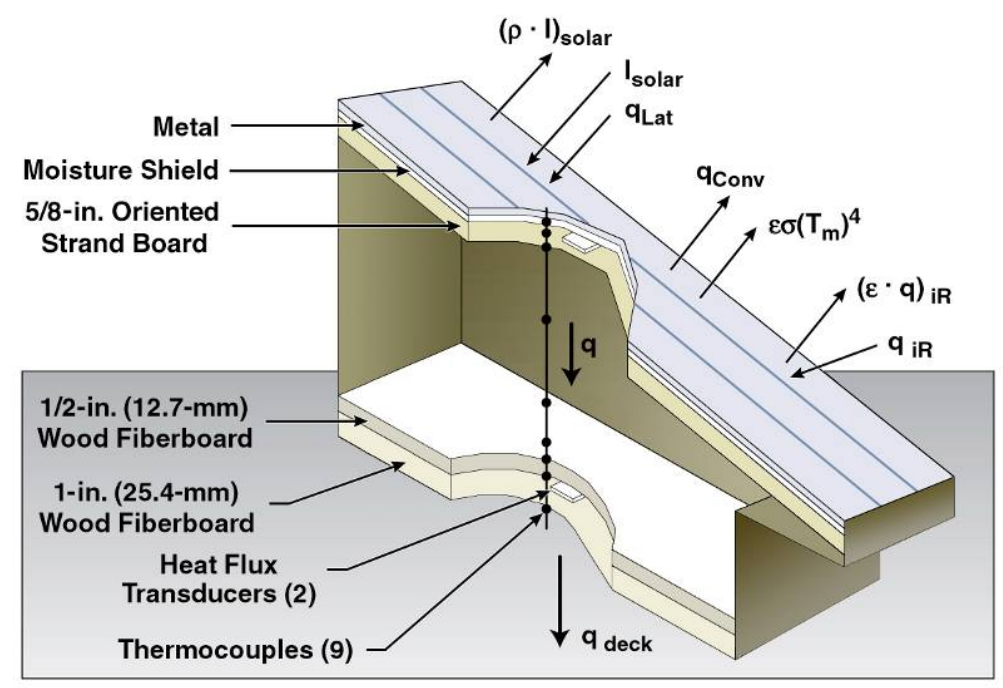

Fig. 7. Setup of attic assembly showing construction materials, instrumentation, and polyisocyanurate insulation used to isolate the attic from adjacent attics. 


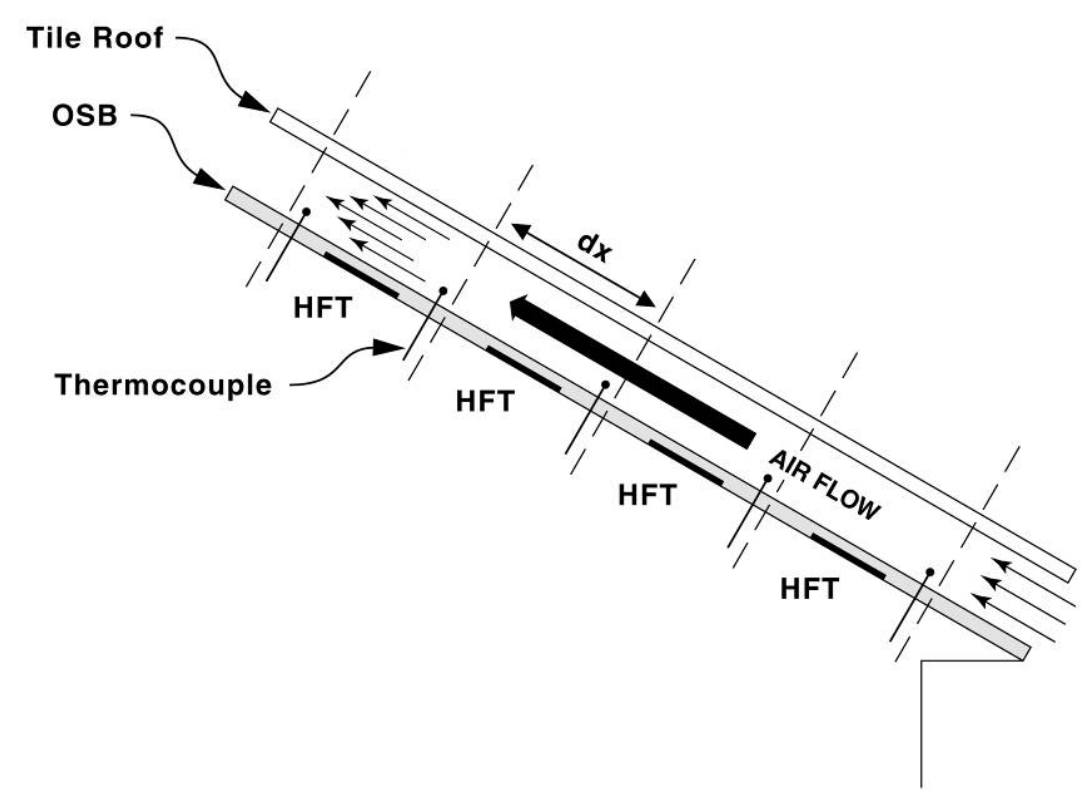

Fig. 8. Instrumentation used on underside of light-gray stone-coated metal shake roof with IrBCPs for validating heat transfer correlations predicting the heat transfer driven by thermally induced airflows. 


\section{SOLAR REFLECTANCE AND THERMAL EMITTANCE}

The solar reflectance and the thermal emittance of a roof surface are important surface properties affecting the roof temperature, which, in turn, drives the heat flow through the roof. The solar reflectance $(\rho)$ determines the fraction of the solar radiation incident from all directions that is diffusely reflected by the surface. The thermal emittance $(\varepsilon)$ describes how well the surface radiates energy away from itself as compared with a blackbody operating at the same temperature. Peak radiation from roofs occurs in the far-infrared region for temperatures on the order of $150^{\circ} \mathrm{F}$ and is sometimes referred to as the infrared emission. The thermal emittance represents the total hemispherical release of electromagnetic radiation over all wavelengths with peak radiation in the far infrared part of the spectrum.

\section{Infrared-Blocking Color Pigments (IrBCPs)}

The complex inorganic color pigments termed IrBCPs in this report are of paramount importance and will literally revolutionize the roofing industry. The energy and cost savings reported by Parker, Sonne, and Sherwin (2002) for white reflective concrete tile and painted metal roofs demonstrated in Ft. Myers, Florida, are promising. However, in the residential market, the issues of aesthetics and durability will limit the acceptance of "white" residential roofing. To homeowners, dark roofs simply blend better with the surroundings than a highly reflective "white" roof. What the public is not aware of, however, is that the aesthetically pleasing dark roof can be made to reflect like a "white" roof in the near infrared spectrum. Miller et al. (2004); Akbari et al. (2004); and Levinson, Berdahl, and Akbari (2004a-b) provide further details about the potential energy benefits and the identification and characterization of dark yet highly reflective color pigments.

\section{Development of Stone-Coated Metals with IrBCPs}

The granules embedded in an asphalt shingle cover about $97 \%$ of the shingle's surface, and shingle manufacturers have applied IrBCPs to the granules to effectively boost the solar reflectance of the shingle. Researchers at LBNL and ISP Mineral replaced a standard black pigment used to color the granules of a dark absorptive shingle with IrBCPs and observed an increase in solar reflectance from 0.04 to 0.12 (Akbari, Levinson, and Berdahl 2004). Their spectrometric work showed that the coating of IrBCP paint was too thin and allowed transmission of some solar irradiance in the near infrared spectrum. A thin titanium dioxide $\left(\mathrm{TiO}_{2}\right)$ white paint was therefore applied as an undercoat prior to painting the granules with IrBCPs (Fig. 9). The undercoat helped increase the shingle's solar reflectance to 0.16 . Electromagnetic radiation that penetrated the IrBCP paint was reflected back by the white undercoating. Next, LBNL and ISP Minerals tried increasing the thickness of the $\mathrm{TiO}_{2}$ undercoat to minimize the absorption of radiant energy, and they successfully increased the solar reflectance to 0.18 . Multiple coatings also effectively increased solar reflectance, as demonstrated by the $3 \mathrm{M}$ Industrial Minerals Company, which developed cool granules in gray, brown, tan,

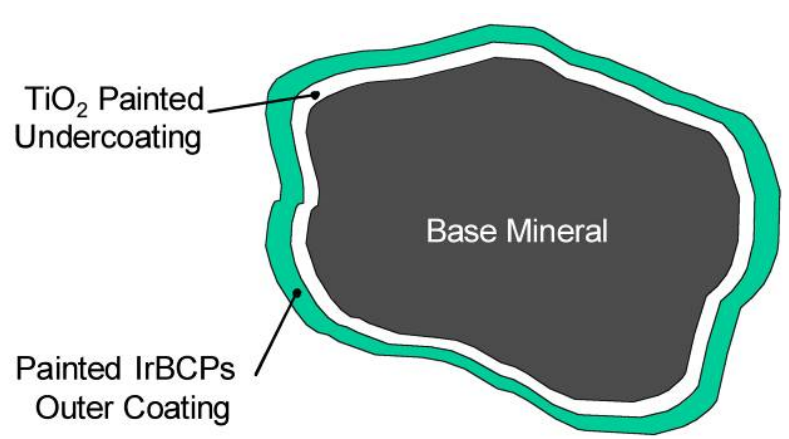

Fig. 9. A two-coat paint process can use existing infrastructure to manufacture infrared reflective granules for stone-coated metals and asphalt shingles. 
and blue-gray with solar reflectances exceeding 0.25. Similar gains are also achievable for granules used to cover stone-coated metals. The coverage provided by granules, due to their smaller size, is at least as good as that provided by asphalt shingles.

Several granular-coated products of a given color were evaluated for the importance of the size of the aggregate, the type of IrBCP, and the effect of applying IrBCPs to the primer/binder adhesive holding the aggregate in place. Weathered Timber is a commercially available stone-coated metal product that has a solar reflectance of 0.06. Research at ORNL with red quartz and red shingle granules showed that the smoother quartz surface provides higher reflectance because quartz is made in spheres and is more reflective than crushed granite. The finding was confirmed by data from LBNL and ISP Mineral on asphalt shingle granule blending, which showed a larger increase in solar reflectance when infrared reflective (IR) pigments are added to larger size aggregates. Pigment testing showed that adding IrBCPs to the base granite adhesive increased the solar reflectance only 0.03 reflectance points over an adhesive with conventional pigment. The results show that little irradiance penetrates through the multiple finishing layers of the stone-coated metals (Fig. 1). The combination of blending a weathered timber color with individual granules that are slightly lighter, yet more reflective, and overcoating the stone chips with a clear acrylic overglaze increased solar reflectance from 0.06 to about 0.19 (Fig. 10). The acrylic overglaze is typically applied as a final coating and gives the stone granules a semigloss appearance. The acrylic finish bonds to the granules and encapsulates them with a coating that enhances the panel's resistance to physical damage. Next, IrBCPs were added to the granules and to the acrylic base coat adhesive, and the solar reflectance was again increased to 0.22 . The addition of IrBCP to the overglaze further increased the solar reflectance above 0.25 , which is the threshold set for steep-slope roofing by Energy Star (Fig. 10). Given these results for improving solar reflectance, DuraLoc and Metro Roof Products made prototype stone-coated metal shakes and tiles with solar reflectance that met the 0.25 threshold and installed them on the ESRA steep-slope assembly for field testing.

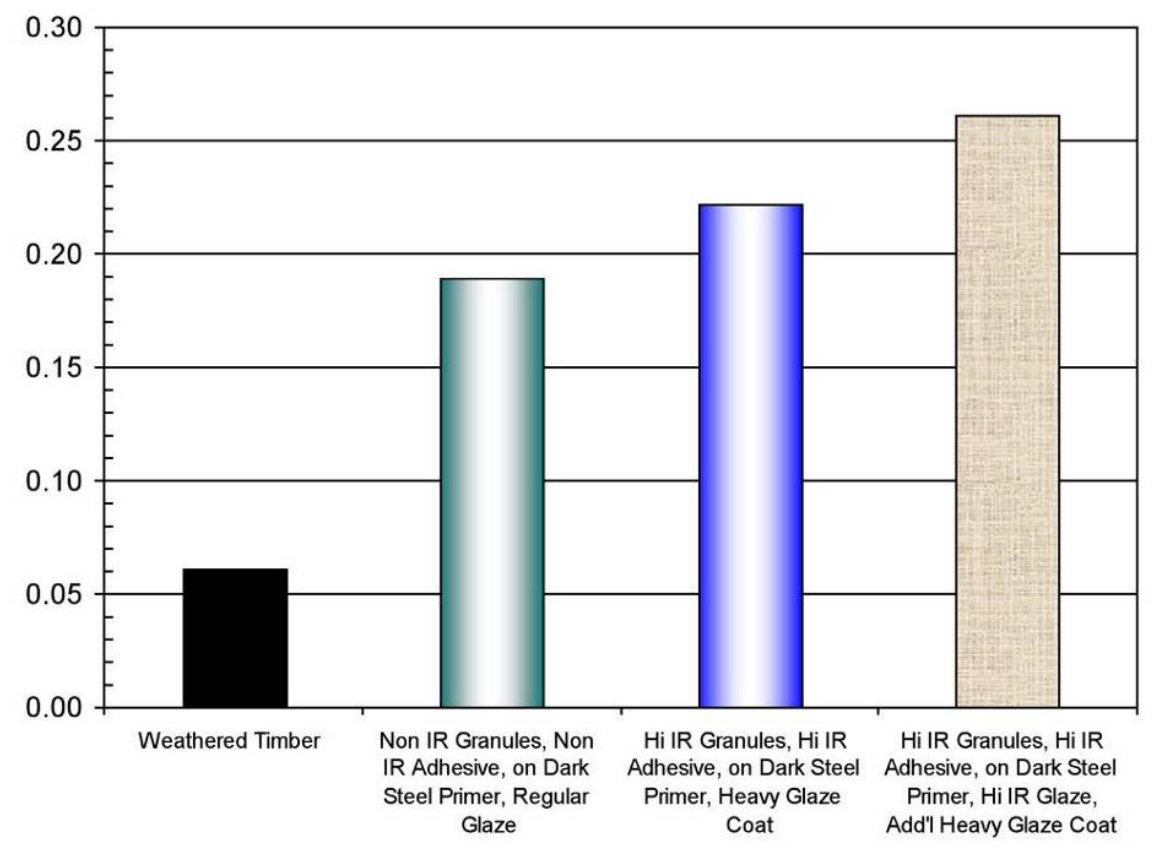

Fig. 10. Effect of IrBCPs and an acrylic overglaze on the solar reflectance of stone-coated metal coupons tested by ORNL and Metro Roof Products. 


\section{Effects of Climatic Soiling}

Solar reflectance measures of the stone-coated metal and painted metal roofs exposed at ORNL were collected quarterly. These data are shown in Fig. 11. The light-gray shakes had an initial solar reflectance of about 0.25 and an initial thermal emittance of 0.90 . The underside metal of the shakes has a thermal emittance of 0.34 and acts as a radiant barrier for the roof structure. We spray-painted a black acrylic laquer on the underside of the light-gray shake installed in Lane 10 to observe differences in deck heat flow due to the underside thermal emittance (see Table 1).

After almost 1/1/2 years of exposure, the light-gray shakes showed about a $10 \%$ loss in solar reflectance. The data trends are also showing a leveling out in the loss of reflectance, a trend consistent with observations from previous studies by Wilkes et al. (2000) and Miller et al. (2002). The dark-gray shake actually showed a slight increase in solar reflectance due to the accumulation of airborne contaminants. Dust tends to lighten a darker color. The painted metal roof with IrBCPs had the highest solar reflectance of the roofs tested, about 0.29 . Also, it has lost only about $3.5 \%$ of its original solar reflectance. The S-mission stone-coated metal tile with IrBCPs had a higher solar reflectance than its S-mission tile counterpart (Fig. 11) because it has a lighter, almost orange color as compared with the darker reddish brown of the S-mission tile with conventional pigments. The S-mission tile with IrBCPs had incurred a 6\% loss in reflectance; the fact that its darker counterpart showed no losses is attributed to the effect of airborne dust.

Coupons of the stone-coated metal prototypes are also under field exposure in 7 of the 16 California climate zones. The coupons have been exposed for only 0.7 year; however, the California exposure is showing trends similar to those observed in East Tennessee. The light-gray shake loses some reflectance, while the reflectance of the darker gray stays the same or increases slightly because of airborne dust.

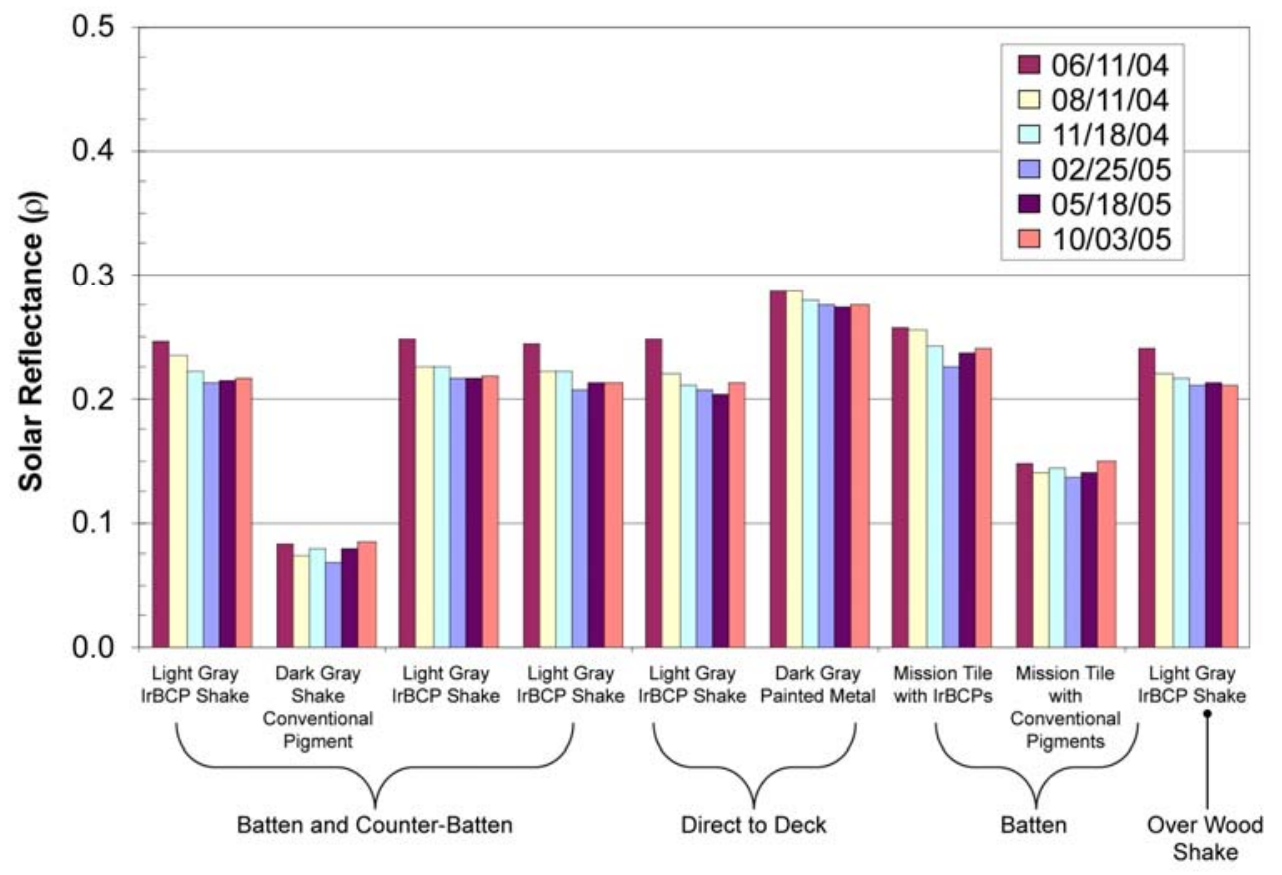

Fig. 11. Solar reflectance for stone-coated metals and painted metal roofs exposed to the weather of East Tennessee. 
The thermal emittance of the stone-coated metal roofs has not changed much, remaining relatively constant at about 0.85. Wilkes et al. (2000) and Miller et al. (2002) also observed that the emittance of coatings and thermoplastic membranes did not change markedly over time, but that thermal emittance and reflectance effects are intertwined. 


\section{FIELD TEST RESULTS}

Stone-coated metal roofs provide multiple hazard protection from fire and wind. Their light weight and durability ${ }^{4}$ are making them more and more popular with homeowners in the western and some southern states. Thermal performance data collected from the attic test assembly at ORNL show the prototype roofs to be energy-efficient because of the venting that occurs on the underside of the tile and also because of the increase in solar refectance achievable with IrBCPs.

As early as 1942, the Federal Housing Administration (FHA 1942) set an attic ventilation ratio requirement of 1:300 (soffit and ridge vent openings to attic footprint) for convective cooling of attic air and for minimizing condensation on the underside of the roof sheathing as a preventive maintenance measure. The importance of convection cooling of attic air is controversial. The ridge vent for the stone-coated metal shake and asphalt shingle roofs were opened for the summer of 2005 to observe the effects of attic ventilation and, more importantly, the effect of unrestricted airflow within the inclined air gap formed under the stone-coated metal roofs. Venting of attic spaces, and its effect on heat transmission and moisture, have been studied at some length, but little has been done to analyze the venting and flow patterns observed in the inclined channel created by batten and counterbatten deck constructions. Rose (1995) gives an overview of the evolution of attic venting, and Romero and Brenner (1998) instrumented a test building for the study of ridge venting and the associated flow within the attic space. Though few studies are available on heat transfer within the narrow air channel in counter-batten installations, insight can be gained from the work done on attic ventilation and from experimental studies of heat transfer in inclined ducts. Ozsunar, Baskaya, and Sivrioglu (2001) studied the effects of inclination on convection within a large-aspect-ratio duct heated from below. Beal and Chandra (1995) studied heat transfer through direct-nailed tile roofs and counter-batten tile roofs as compared with heat transfer through direct-nailed asphalt shingle roofs. Relative to the asphalt shingles, tile reduced heat transmission by $39 \%$ in the direct-nailed configuration and by $48 \%$ for the counter-batten configuration.

\section{Summer Field Exposure}

A clear, cloudless summer day was selected to display the effects of the IrBCPs on the surface temperatures of the roof with stone-coated metal shingles compared with the roof with asphalt shingle (Fig. 12a) and the corresponding attic temperatures for the week in which the day occurred (Fig. 12b). The legend in Fig. 12a provides details for each test roof assembly. For example, the descriptive phrase "Shk-LG-IRRagg-Upt-CB (SR25E90)" defines a stone-coated shake roof (Shk) which is light gray (LG) with IrBCPs applied to the aggregrate and glaze (IRRagg); the underside of the metal roof is unpainted (Upt), and the roof is offset-mounted from the roof deck by nailing the shakes to a batten and counter-batten construction (CB). The legend also defines solar reflectance and thermal emittance for each test roof, with "SRxx" indicating the initial solar reflectance of the respective test roof and "Eyy" defining the initial thermal emittance. For instance, the control asphalt-shingle roof is labeled SR093E89; its freshly manufactured surface properties are therefore a reflectance of 0.093 and an emittance of 0.89 .

Results observed at solar noon on August 2, 2005, show that the light-gray shake with IrBCPs (SR246E90) had a surface temperature about $10^{\circ} \mathrm{F}$ cooler than the control roof (SR093E89). All stone-coated metal roofs had roughly this same $10^{\circ} \mathrm{F}$ drop in surface temperature (Fig. 12a). The

\footnotetext{
${ }^{4}$ Stone-coated metal roofs are warranted for more than 50 years.
} 


$$
\begin{array}{ll}
\text { - Control - Asphalt Shingle (SR093E89) } & \text { - Shk-LG-IRRagg-Upt-CB (SR246E90) } \\
\text { - Shk-DG-CNVagg-Upt-CB (SR08E90) } & \text { - Shk-LG-IRRagg-Pt-CB (SR25E90) } \\
\text { - Shk-LG-IRRagg-UPt-CB-Fascia Vent (SR244E90) } & - \text { Shk-LG-IRRagg-UPt-DDk (SR25E90) } \\
\text { - S-Mission-TC-IRRagg-UPt-Batten (SR257E90) } & - \text { S-Mission-TC-STDagg-UPt-Batten (SR15E90) } \\
\text { - PVDF Metal-DG-IRRPnt-UPt-DDk (SR287E90) } & - \text { Shk-LG-IRRagg-UPt-CB over Cedar Shake (SR24E90) }
\end{array}
$$

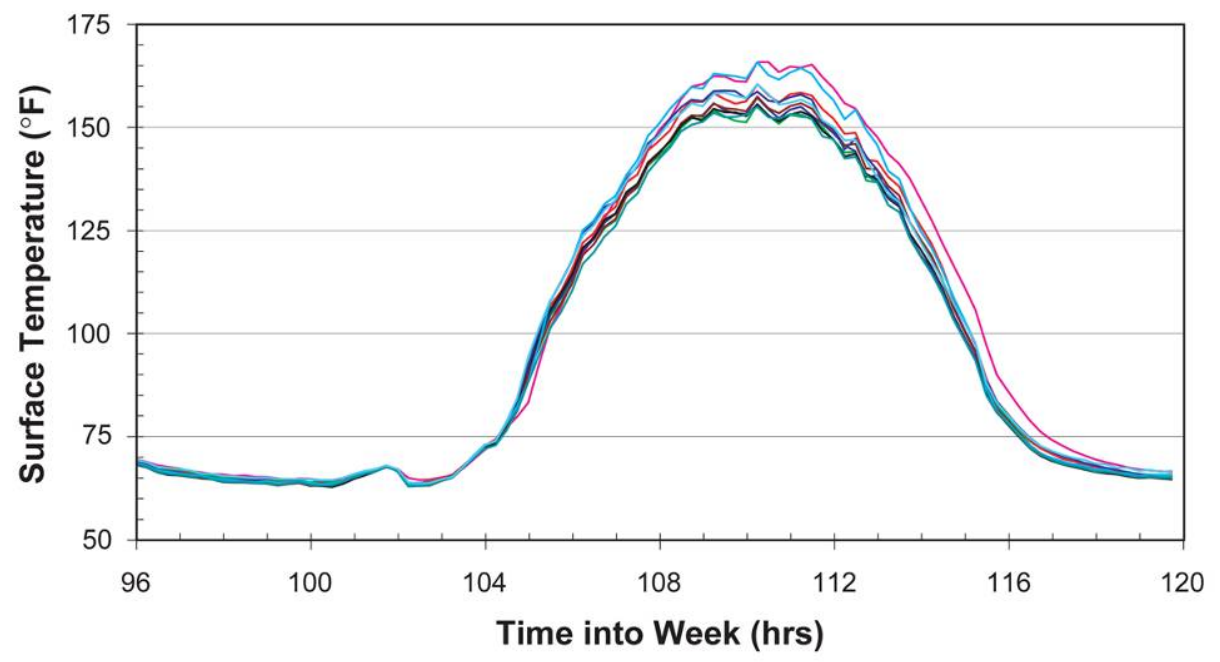

(a) Surface temperatures for the stone-coated metal and the shingle roofs.

$$
\begin{array}{ll}
\text { - Control - Asphalt Shingle (SR093E89) } & \text { - Shk-LG-IRRagg-Upt-CB (SR246E90) } \\
\text { - Shk-DG-CNVagg-Upt-CB (SR08E90) } & \text { - Shk-LG-IRRagg-Pt-CB (SR25E90) } \\
\text { - Shk-LG-IRRagg-UPt-CB-Fascia Vent (SR244E90) } & - \text { Shk-LG-IRRagg-UPt-DDk (SR25E90) } \\
\text { - S-Mission-TC-IRRagg-UPt-Batten (SR257E90) } & - \text { S-Mission-TC-STDagg-UPt-Batten (SR15E90) } \\
\text { - PVDF Metal-DG-IRRPnt-UPt-DDk (SR287E90) } & - \text { Shk-LG-IRRagg-UPt-CB over Cedar Shake (SR24E90) }
\end{array}
$$

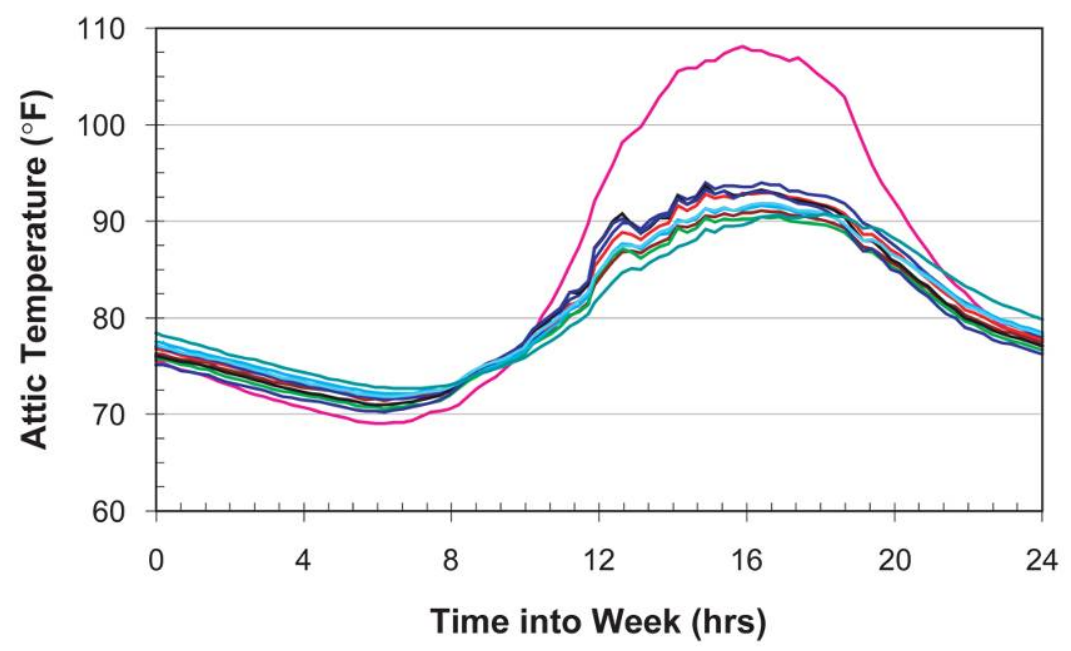

(b) Attic air temperatures measured at the center of each attic assembly.

Fig. 12. Surface temperatures (a) and attic air temperatures (b) for the stone-coated metal roofs and the asphalt shingle control as measured between July 29 and August 5, 2005. 
similarity in daytime surface temperatures occurs because there are only about 15 points of reflectance difference between the stone-coated metal roofs and the control roof. However, the attic air temperature (Fig. 12b) reveals a better picture of differences. Over the seven-day period, the attic air temperatures for several of the stone-coated metal roofs and the PVDF painted metal roof are 15 to $20^{\circ} \mathrm{F}$ cooler at solar noon than the attic with the control shingle. IrBCPs are not fully responsible for the reduced attic temperatures. The venting occurring along the underside of the metal roofs contributes significantly.

Heat flow penetrating through the roof deck is also reduced by the combination of higher solar reflectance and underside venting (Fig. 13). As an example, the light-gray shake roof [Shk-LGIRRagg-Upt-CB (SR246E90)] reduced the heat flow penetrating the roof deck over the daylight hours by $45 \%$ compared with that measured for the attic assembly with asphalt shingle (SR09E89) roof. The flux entering the conditioned space in many of the cases shown in Fig. 13 is half that for the control asphalt shingle. Therefore, underside venting of the stone-coated metal roof is just as important as the effects of IrBCPs for improving the thermal performance of buildings with steepslope roofs.

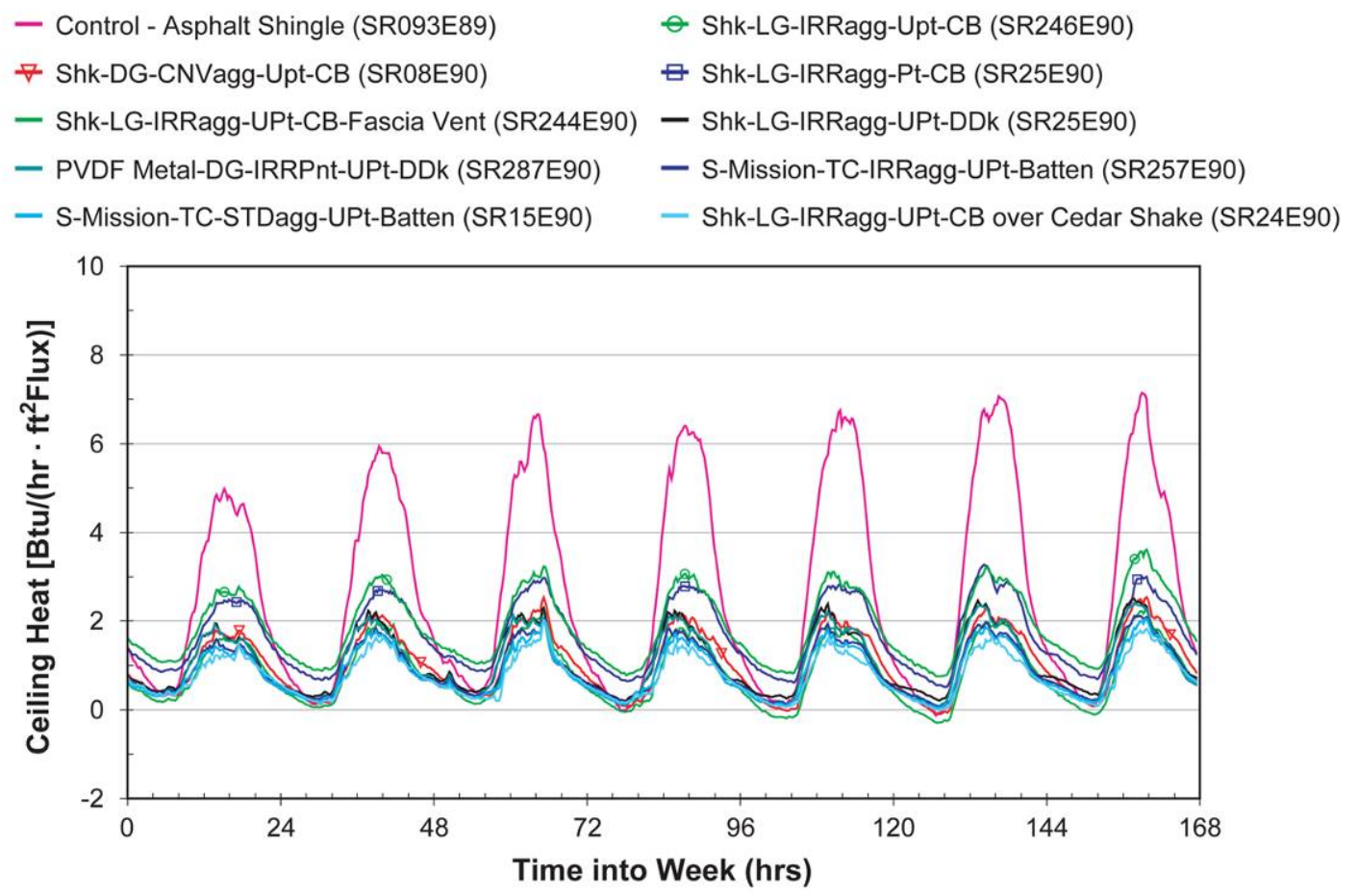

Fig. 13. Heat penetration through the ceiling of tested attic assemblies with ridge vent open.

In light of these findings, the next several figures focus on the roof deck heat flow for the asphalt shingle control as compared with that for the light-gray stone-coated shake [Shk-LG-IRRagg-Upt-CB (SR246E90)] and just one other steep-slope assembly per figure to view the separate effects of solar reflectance, underside thermal emittance, deck venting, roof profile and retrofit applications over existing roof structures. 


\section{Effect of Underside Venting (Solar Reflectance and Thermal Emittance Fixed)}

The dark-gray stone-coated shakes (SR08E90) have a solar reflectance and thermal emittance almost identical to that of the control asphalt shingle roof SR093E89. However, the asphalt shingle is directly nailed to the roof deck. It has no venting along its underside, unlike the dark-gray shake, which is attached to a batten and counter-batten arrangement. Both assemblies did, however, have attic ventilation through soffit and ridge vents. Venting the underside of the dark-gray stone-coated metal shake (i.e., subtile venting) caused significant reductions in heat flow crossing the deck during solar noon (Fig. 14).

Deck heat flows for the seven-day period around August 2 (Fig. 14) integrated over the daylight hours are provided in Table 2. The interior walls of each attic assembly were insulated with at least $5 \mathrm{in}$. of foam insulation. Given the measurements of heat flow crossing the roof deck and the attic ceiling, the amount of heat removed by attic ventilation and roof deck venting can be approximated by the energy balances shown in Eqs. (1) and (2):

$$
\begin{gathered}
\mathrm{Q}_{\text {Attic vent }}=\frac{\mathrm{Q}_{\text {Roof Deck }}^{\mathrm{HFT}}-\mathrm{Q}_{\text {Attic floor }}^{\mathrm{HFT}}}{\operatorname{coS}(\theta)} \\
\mathrm{Q}_{\text {Deck vent }}=\frac{\mathrm{Q}_{\text {Solar Abs }}-\mathrm{Q}_{\text {Mass }}-\mathrm{Q}_{\text {Roof Deck }}^{\mathrm{HFT}}}{\operatorname{COS}(\theta)}
\end{gathered}
$$

where

$$
\begin{array}{ll}
\mathrm{Q}_{\text {Solar Abs }} & =I_{\text {Solar }}\left(1-\rho_{S R}\right)-\hbar\left(T_{S}-T_{O D \text { Air }}\right)-\varepsilon \sigma\left(T_{S}^{4}-T_{\text {Sky }}^{4}\right) \\
\mathrm{Q}_{\text {Mass }} & =\Delta \rho \mathrm{C}_{\mathrm{P}} \frac{\partial \mathrm{T}}{\partial \mathrm{t}} \text { (thermal mass of roof cover and OSB decking included in } \mathrm{Q}_{\text {Mass }} \text { ) } \\
\mathrm{Q}_{\text {Attic ceiling }}^{\mathrm{HFT}} & =\text { heat flux transducer (HFT) embedded in attic floor } \\
\mathrm{Q}_{\mathrm{Roof} \text { deck }}^{\mathrm{HFT}} & =\text { heat flux transducer (HFT) embedded in roof deck }
\end{array}
$$

The dark-gray stone-coated metal shakes and the asphalt shingles have almost identical reflectance and emittance characteristics, yet the heat flow crossing the roof deck of the dark-gray shake is only $70 \%$ of the heat flow crossing the roof deck of the asphalt control shingle (Table 2). The $30 \%$ reduction in heat flow is due to deck venting despite the slight decrease in attic venting occurring under the dark-gray shake.

Subtile venting of the dark-gray shake is four times larger than is attic ventilation (Table 2). Thus, subtile venting of the dark-gray shake lowers the heat content of the attic and the interior surface temperatures, which in turn means that lower amounts of heat penetrate the attic's floor. Again, venting (subtile and attic ventilation) reduced the heat flow through the attic floor by about $65 \%$ of the heat flow crossing the floor of the conventional attic assembly (326.6 vs $112.2 \mathrm{Btu} / \mathrm{ft}^{2}$ ) with the asphalt shingle roof.

\section{Effect of Solar Reflectance (Fixed Deck Vent)}

The steep-slope assemblies Shk-LG-IRRagg-Upt-CB (SR246E90) and Shk-DG-CNVagg-Upt-CB (SR08E90) have identical batten and counter-batten constructions and unpainted undersides. Both have soffit and ridge vents supporting attic ventilation. The solar reflectance of the light-gray shake is 
0.25 ; reflectance for the darker gray shake is 0.08 . The 0.17 increase in solar reflectance caused the heat flow crossing the roof deck of the light-gray shake to be less than the heat flow crossing the roof deck of the dark-gray stone-coated shake. The reduction is about $15 \%$ of the heat crossing the deck of the control shingle roof (Table 2). The 15\% reduction is based on the daytime integration of deck heat flow; the 30\% reduction due to deck venting of the dark stone-coated shingle (previously discussed) can be added to the $15 \%$ reduction due to IrBCPs to yield a total $45 \%$ reduction in heat flow due to both underside venting and increased solar reflectance. The combined results (Fig. 14) observed using both IrBCPs and subtile venting show that ventilating the deck is just as important as the boost in solar reflectance and may be the stronger player in reducing the heat gain to the attic assembly. It is interesting to note that the heat flow due to subtile venting of the hotter dark-gray

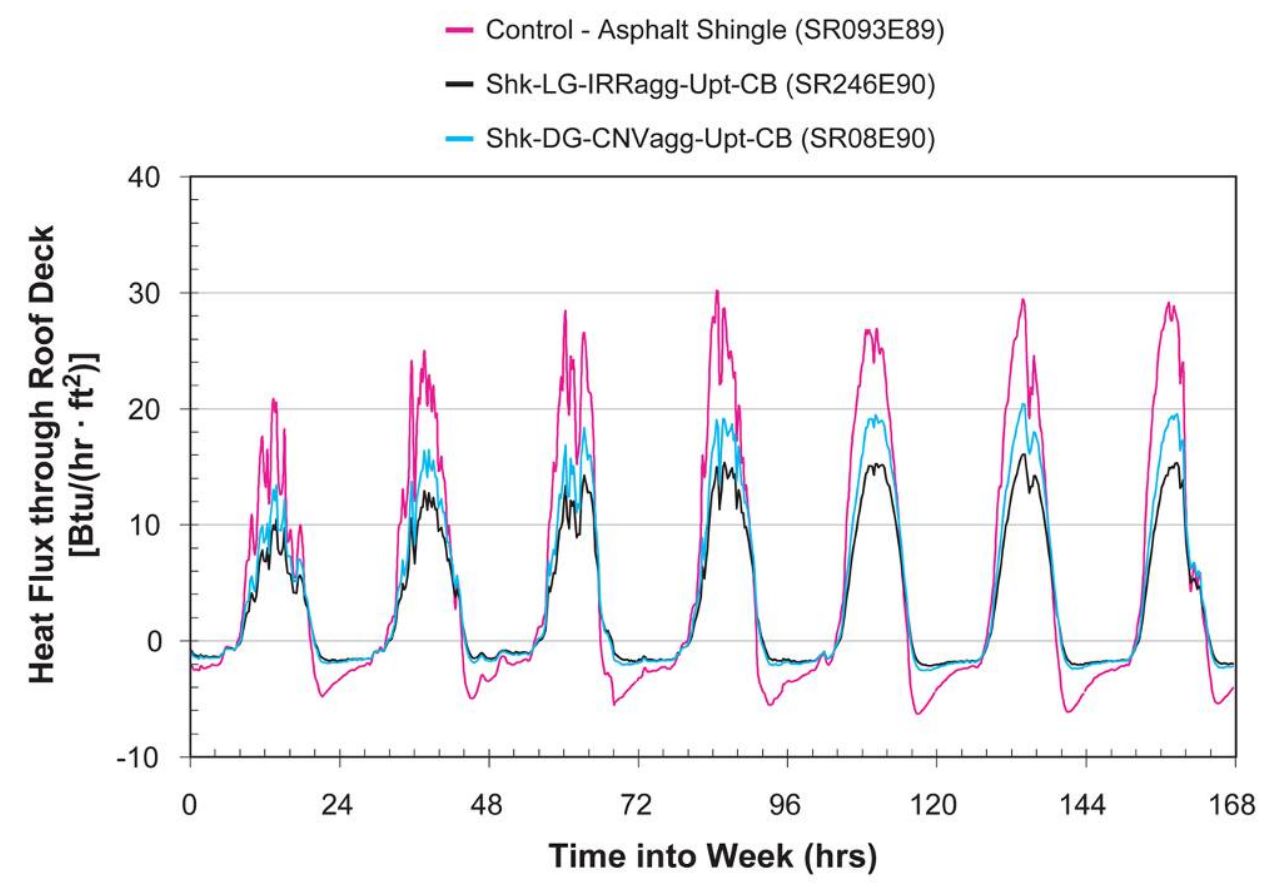

Fig. 14. Effect of solar reflectance for two stone-coated shake roofs on battens and counter-battens and effect of underside venting for a stone-coated metal roof as compared with a direct-nailed shingle roof.

Table 2. Roof deck and attic floor heat flows $\left(B t u / \mathrm{ft}^{2}\right)$ integrated over the daylight hours for a week of July data

\begin{tabular}{lccc}
\hline & $\begin{array}{c}\text { Control shingle } \\
\text { (SR093E89) }\end{array}$ & $\begin{array}{c}\text { Shk-LG-IRRagg-Upt- } \\
\text { CB (SR246E90) }\end{array}$ & $\begin{array}{c}\text { Shk-DG-CNVagg-Upt- } \\
\text { CB (SR08E9) }\end{array}$ \\
\hline Roof deck & 1216.4 & 670.3 & 853.9 \\
Attic floor & 326.6 & 95.5 & 112.2 \\
$\mathrm{Q}_{\text {Attic vent }}$ & 889.7 & 574.8 & 741.8 \\
$\mathrm{Q}_{\text {Deck vent }}$ & & 1280.6 & 2703.8 \\
\hline
\end{tabular}

Note: Heat flows are corrected for projected attic floor area. Daylight is defined as the period when the solar flux normal to roof exceeds $30 \mathrm{Btu} / \mathrm{hr} \cdot \mathrm{ft}^{2}$. 
shake is more than double the amount of heat flow swept away from the deck of the light-gray shake (Table 2). The hotter dark-gray shake induces greater bouyancy-induced airflows, and there is therefore an optimum tradeoff between solar reflectance and subtile venting.

\section{Effect of Thermal Emittance on Roof's Underside (Fixed Deck Vent)}

The steep-slope assemblies Shk-LG-IRRagg-Upt-CB (SR246E90) and Shk-LG- IRRagg -Pt -CB (SR25E90) have the same surface color and are both on batten and counter-batten constructions. The underside of the one roof is unpainted (Upt) and has a thermal emittance of 0.34 . The other roof's underside is painted (Ptd), and its thermal emittance is 0.85 . Lowering the underside emittance from 0.85 to 0.34 had minor effects on the roof deck heat transfer, as seen in Fig. 15. The reduction is only about $2.5 \%$ of the deck heat flow crossing the conventional asphalt shingle roof (Table 3 ). The effect appears additive to the effects of IrBCPs and underside venting. Leaving the metal on the underside unpainted yields the better cooling and heating seasonal performance.

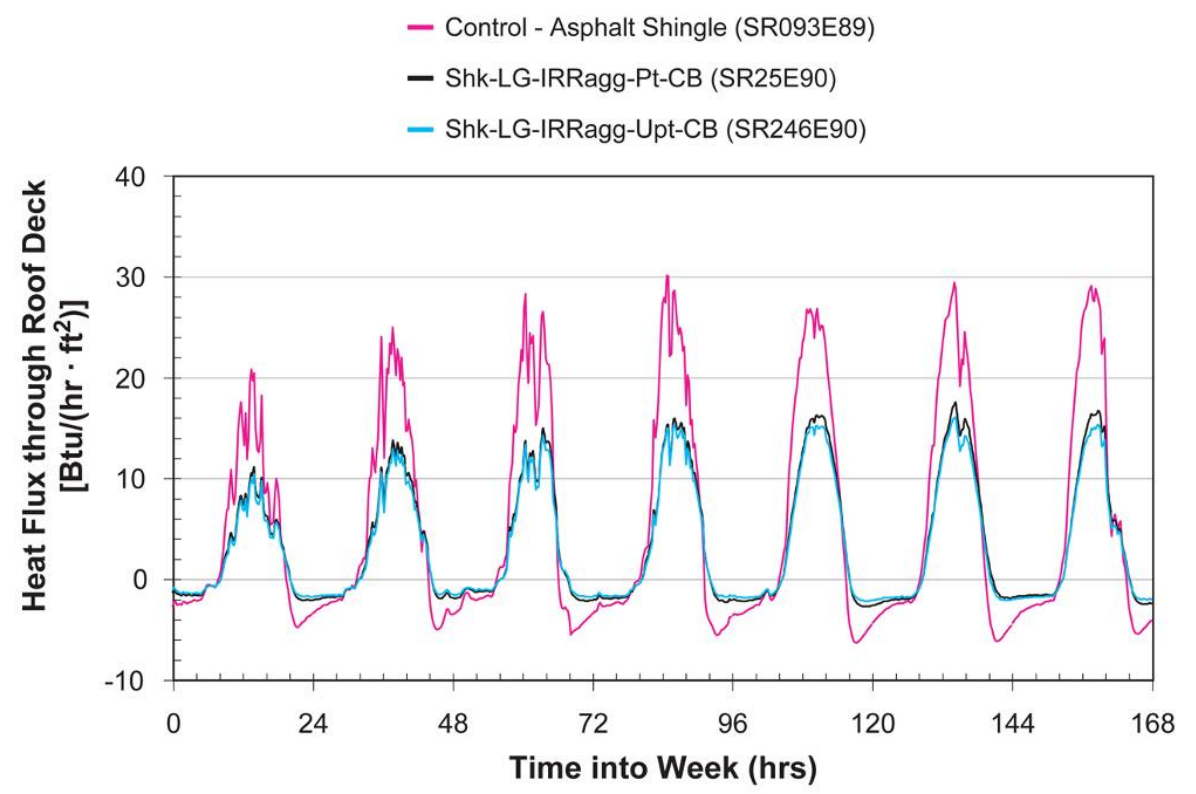

Fig. 15. Effect of thermal emittance on the underside of two stone-coated metal roofs, one with a thermal emittance of 0.34 and the other with a thermal emittance of 0.85 .

Table 3. Effect of thermal emittance on the underside of a stone-coated metal roof

\begin{tabular}{lccc}
\hline & \multicolumn{3}{c}{$\begin{array}{c}\text { Heat flow during daylight } \\
\left(\text { htulft }^{2}\right)\end{array}$} \\
\cline { 2 - 4 } & $\begin{array}{c}\text { Control shingle } \\
\text { (SR093E89) }\end{array}$ & $\begin{array}{c}\text { Shk-LG-IRRagg-Upt- } \\
\text { CB (SR246E90) } \\
\text { (Underside } \varepsilon=0.34)\end{array}$ & $\begin{array}{c}\text { Shk-LG- IRRagg-Pt -CB } \\
\text { (SR25E90) } \\
\text { (Underside } \varepsilon=0.85)\end{array}$ \\
\hline Roof deck & 1216.4 & 670.3 & 723.4
\end{tabular}

${ }^{a}$ Heat flows are corrected for projected attic floor area. Daylight is defined as the period when the solar flux normal to roof exceeds $30 \mathrm{Btu} / \mathrm{hr} \cdot \mathrm{ft}^{2}$. 


\section{Effect of a Fascia Vent (Fixed Deck Vent)}

Fascia venting of the light-gray shakes (see Fig. 3, fifth lane from the right of the stone-coated metal test assembly) did not reduce the heat transfer at the deck any more than was observed for the lightgray stone-coated metal shake on battens and counter-battens [Shk-LG-IRRagg-Upt-CB (SR246E90)]. Tracer gas experiments revealed that the fascia vent did not appreciably increase the underside airflow. [See the section on tracer gas measurements (page 30) for more details.]

\section{Effect of Direct-to-Deck vs Batten and Counter-Batten}

Light-gray stone-coated shakes were direct-nailed to the roof deck to further quantify the effect of deck venting. Direct nailing of painted PVDF metal shakes and light-gray stone-coated metal shakes increased the heat transfer entering the roof deck as compared with the light-gray shake on battens and counter-battens (Fig. 16.). As already stated, offset-mounting the light-gray stone-coated metal shakes from the roof deck and increasing the solar reflectance from 0.093 to 0.246 caused a $45 \%$ drop in the heat flux entering the roof deck. Attaching the stone-coated metal shakes directly to the deck diminished the benefit by about $14 \%$ (Table 4 ), and rather than a $45 \%$ reduction, about a $30 \%$ reduction was measured because of the effect of solar reflectance and the reduced air gap still created between the panels and the decking. Reflectance is 0.25 for the stone-coated metal shake, 0.29 for the painted PVDF metal shake, and 0.093 for the asphalt shingle.

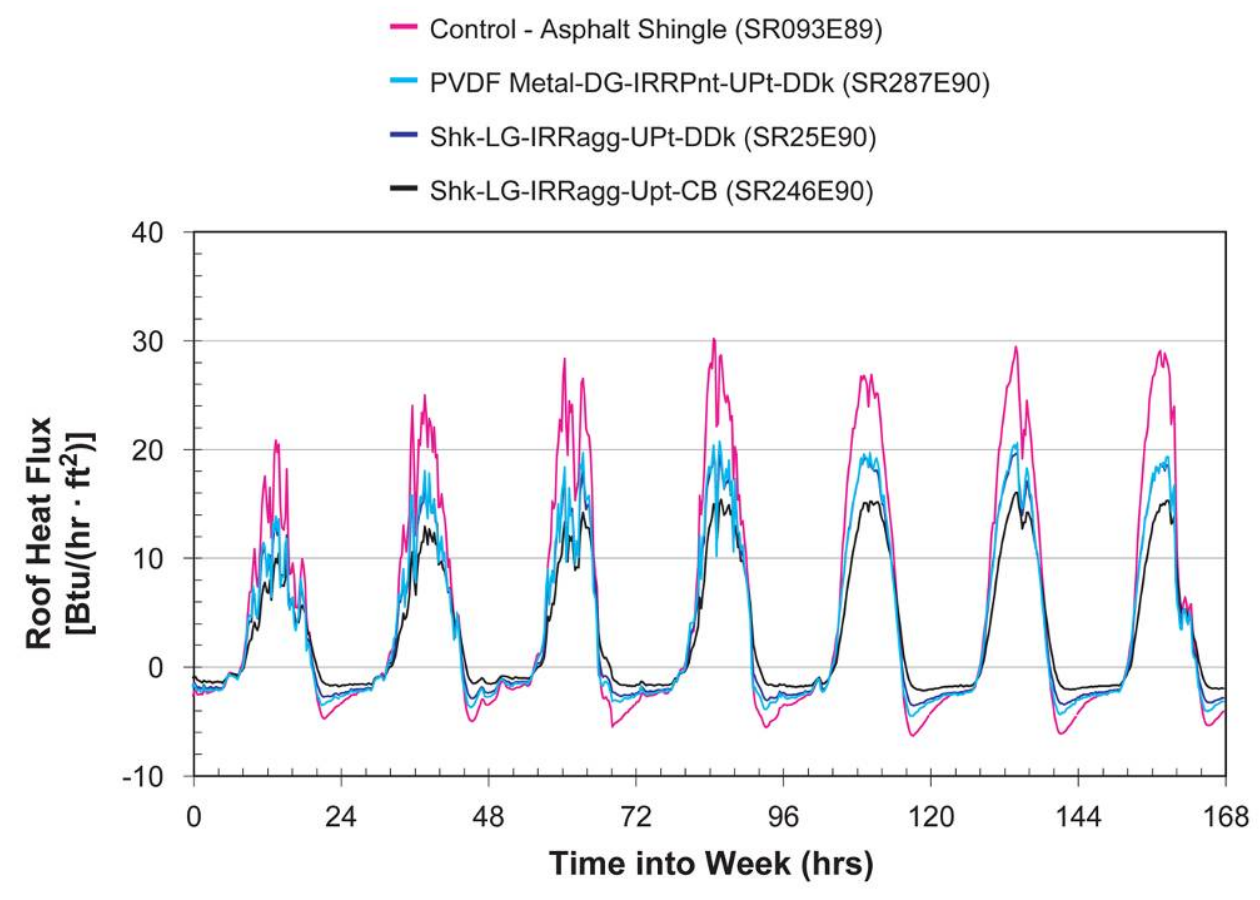

Fig. 16. Effect of direct-nailing a stone-coated metal shake and a PVDF metal shake, as opposed to placing the shake profile on battens and counter-battens. 
Table 4. Heat flow in direct-to-deck attachment of stone-coated and painted metal roofs (Btu/ft $\left.{ }^{2}\right)$

\begin{tabular}{lcccc}
\hline & $\begin{array}{c}\text { Control } \\
\text { shingle } \\
\text { (SR093E89) }\end{array}$ & $\begin{array}{c}\text { Shk-LG-IRRagg- } \\
\text { Upt-CB } \\
\text { (SR246E90) }\end{array}$ & $\begin{array}{c}\text { Shk-LG-IRRagg- } \\
\text { UPt-DDk } \\
\text { (SR25E90) }\end{array}$ & $\begin{array}{c}\text { PVDF Metal-DG- } \\
\text { IRRPnt-UPt-DDk } \\
\text { (SR287E90) }\end{array}$ \\
\hline Roof deck & 1216.4 & 670.3 & 834.6 & 851.0 \\
\hline
\end{tabular}

Note: Heat flows are corrected for projected attic floor area. Daylight is defined as the period when the solar flux normal to roof exceeds $30 \mathrm{Btu} / \mathrm{hr} \cdot \mathrm{ft}^{2}$.

\section{Effect of Stone-Coated Metal S-mission Tile on Batten}

The stone-coated metal roofs with the S-mission profile were installed on $2 \times 2$ in. battens. A counterbatten was not used, but the tile's cylindrical underside provides a vent channel directly above the batten and underneath the S-mission profile. Both S-mission tile roofs performed well and reduced the heat flow penetrating the roof deck by about $37 \%$ of the flow for the control shingle (Table 5). As a result, the heat flow penetrating the conditioned space dropped about $70 \%$ from that measured for the attic assembly with asphalt shingle roof. Most of the ventilation heat flow is due to subtile venting rather than to the attic. Deck venting accounts for $1525 \mathrm{Btu} / \mathrm{ft}^{2}$ with the S-mission tile with conventional pigments, which is about $70 \%$ of the total ventilation heat flow $(2200.4=675.4+$ 1525.0). Overall, the two S-mission tile systems on battens and the light-gray shake roof on battens and counter-battens demonstrated the best thermal performance of the non-retrofit roof systems tested.

Table 5. The effect on heat flow of shake and S-mission profile on stone-coated metal roofs

\begin{tabular}{lcccc}
\hline & \multicolumn{4}{c}{ Heat flow during daylight hours $^{a}$} \\
& $\begin{array}{c}\text { Control shingle } \\
\text { (BR093E89) }\end{array}$ & $\begin{array}{c}\text { Shk-LG-IRRagg- } \\
\text { Upt-CB } \\
\text { (SR246E9) }\end{array}$ & $\begin{array}{c}\text { S-mission-TC- } \\
\text { IRRagg-Upt-batten } \\
\text { (SR257E90) }\end{array}$ & $\begin{array}{c}\text { S-mission-TC- } \\
\text { CNVagg-Upt-batten } \\
\text { (SR15E90) }\end{array}$ \\
\hline Roof deck & 1216.4 & 670.3 & 761.9 & 768.5 \\
Attic floor & 326.6 & 95.5 & 99.0 & 93.1 \\
$Q_{\text {Attic vent }}$ & 889.7 & 574.8 & 662.9 & 675.4 \\
$Q_{\text {Deck vent }}$ & & 1280.6 & 680.7 & 1525.0 \\
\hline
\end{tabular}

${ }^{a}$ Heat flows are corrected for projected attic floor area. Daylight is defined as the period when the solar flux normal to roof exceeds $35 \mathrm{Btu} / \mathrm{hr}^{-\mathrm{ft}^{2}}$.

\section{Stone-Coated Metal Shake Retrofit over Existing Cedar Shake Roof}

A light-gray stone-coated metal shake roof was installed with battens and counter-battens on top of an existing cedar shake roof. The process is called retrofit roofing. The demand for this type of roofing was investigated for its potential in the residential market. Results show that retrofitting a stonecoated metal roof over an existing residential roof makes good thermal sense. This roof system had the largest reduction in deck heat flow of all roof systems, and it reduced the heat penetrating the deck by $70 \%$ from that measured for the asphalt shingle roof. Also, the added mass of the roof assembly that includes cedar shakes slightly delayed the time of peak heat transfer through the deck (Fig. 17). The load penetrating the conditioned space was reduced $75 \%$ from that measured for the conventional attic assembly with asphalt shingle roof (Table 6). 
Table 6. The effect on heat flow of retrofit of light-gray stone-coated metal shakes over existing cedar shake roof

\begin{tabular}{lccc}
\hline & \multicolumn{3}{c}{$\begin{array}{c}\text { Heat flow during daylight hours } \\
\text { (Btu/ft }{ }^{2} \text { ) }\end{array}$} \\
\cline { 2 - 4 } & $\begin{array}{c}\text { Control shingle } \\
\text { (SR093E89) }\end{array}$ & $\begin{array}{c}\text { Shk-LG-IRRagg- } \\
\text { Upt-CB } \\
\text { (SR246E90) }\end{array}$ & $\begin{array}{c}\text { Shk-LG-IRRagg-Upt-CB } \\
\text { over cedar shake } \\
\text { (SR24E90) }\end{array}$ \\
\hline Roof deck & 1216.4 & 670.3 & 369.0 \\
Attic floor & 326.6 & 95.5 & 78.9 \\
\hline
\end{tabular}

${ }^{a}$ Heat flows are corrected for projected attic floor area. Daylight is defined as the period when solar flux normal to roof exceeds $35 \mathrm{Btu} / \mathrm{hr} \cdot \mathrm{ft}^{2}$.

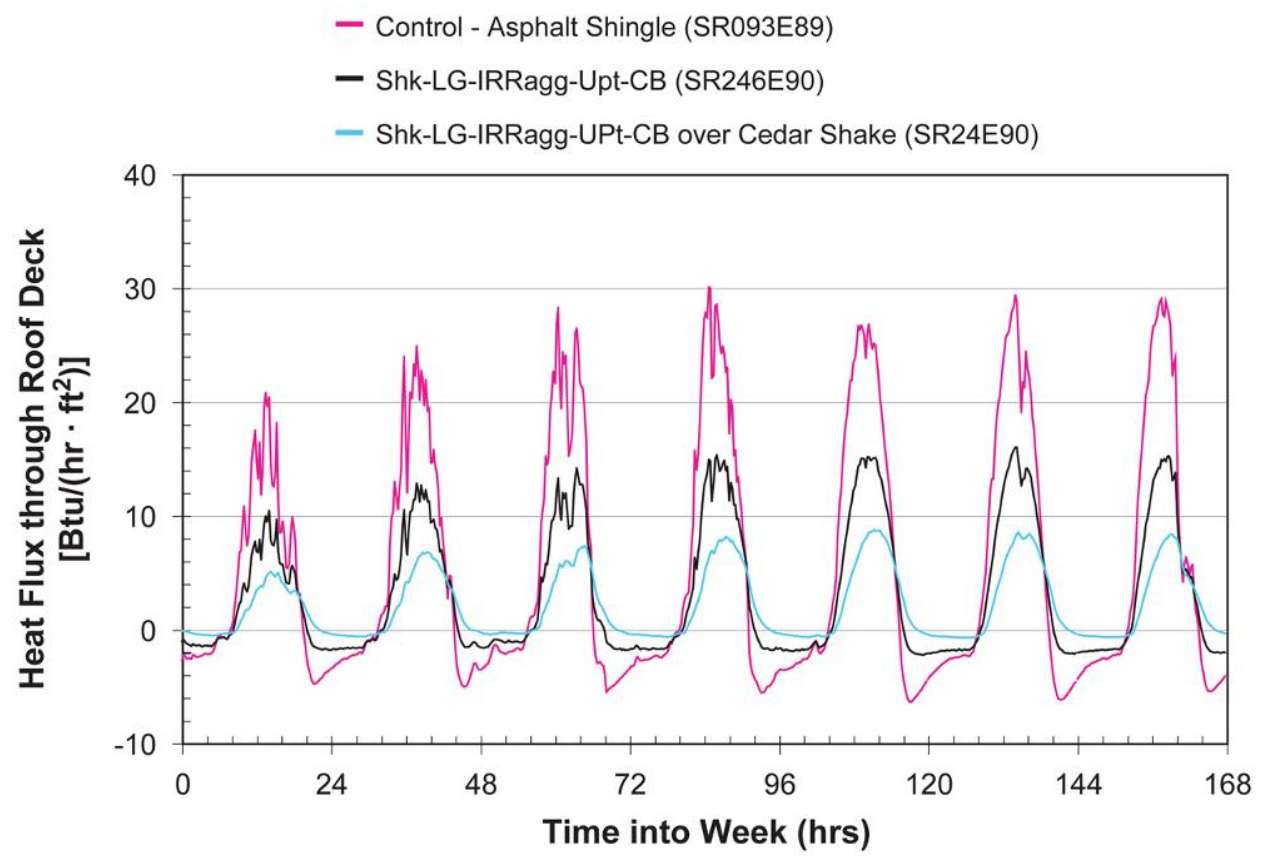

Fig. 17. Effect on heat transfer of retrofit application of stone-coated metal shakes over existing cedar shake roof.

\section{Cooling Seasonal Performance: July 2005}

Field data for the full month of July 2005 were reduced to better observe the cooling season trends in roof heat transfer for the stone-coated metal and asphalt shingle roofs. Data for the HFTs embedded in the south-facing roof deck and the ceiling of each attic assembly were integrated over the daylight hours (red bars in Fig. 18), the nighttime hours (blue bars in Fig. 18), and the 24-hour cycle (gold bars in Fig. 18) and summed for the month. The red and blue bars represent, respectively, the total daytime heat gain and nighttime heat loss crossing the roof deck during July 2005. The gold bars are the net heat transfer into the conditioned space measured from HFTs embedded in the floor of each attic assembly. The measured heat flux crossing the attic floor (ceiling) represents the load that a HVAC system must support to condition the indoor air. 


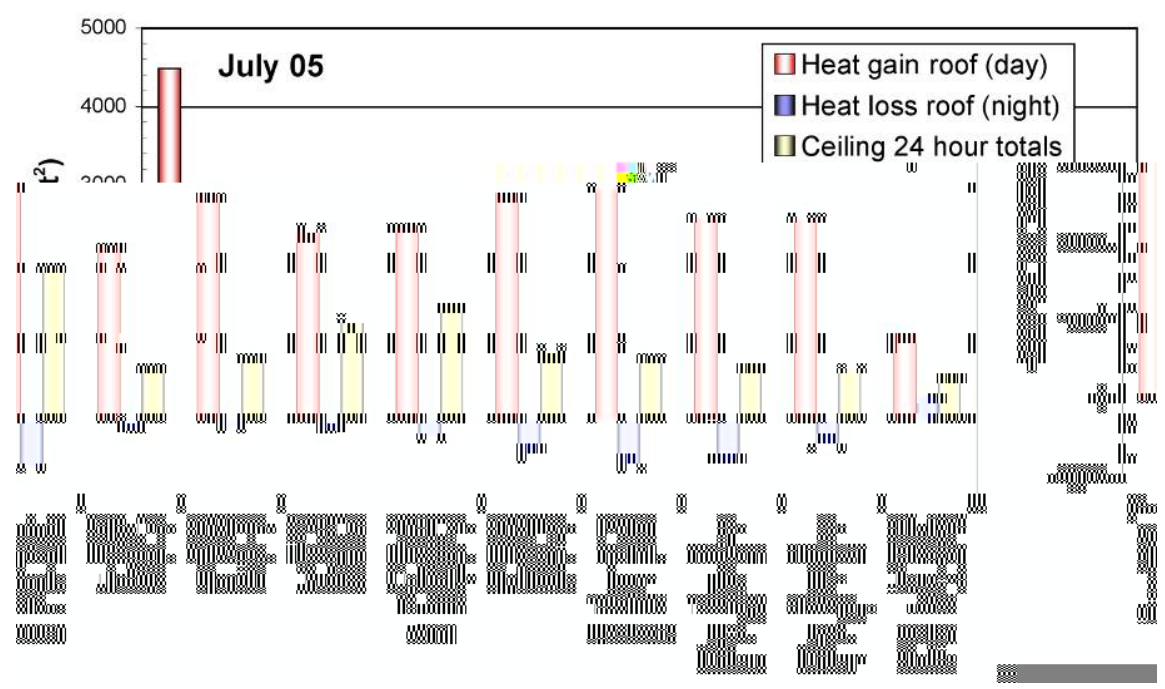

Fig. 18. Integrated heat flow measured through the roof deck for all tile and shingle roofs during July 2005.

The discussion above shows the benefit derived from venting the roof deck. The July monthly integrated heat flow crossing the deck of the dark-gray stone-coated metal roof [Shk-DG-CNVaggUpt-CB (SR08E90)] was reduced by 36\% compared with the heat gain entering the asphalt shingle roof (SR093E89), despite both roofs' having nearly the same solar reflectance and thermal emittance. The reduction is due solely to subtile venting. For all of July, both solar reflectance and subtile venting resulted in a 50.5\% drop in the heat transfer crossing the deck. Proportioning the heat reduction due solely to venting [Shk-DG-CNVagg-Upt-CB (SR08E90)] to the heat reduction due to solar reflectance and venting [Shk-LG-IRRagg-Upt-CB (SR246E90)],

$\overbrace{\frac{36 \% \text { due to subtile venting }}{50.5 \% \text { due to subtile venting and SR }}}^{\text {heat reduction }} \cdot\left[\mathrm{SR} 246_{\text {Shk-LG }}-\mathrm{SR} 093_{\text {Shingle }}\right]$

yields a venting benefit at solar noon that is equivalent to roughly 11 points of solar reflectance. Therefore, the effect of venting the underside of the dark-gray shake roof based on proportioning deck heat transfer [Eq. (3)] equates to about 10 points of solar reflectance for the daylight hours in the month of July 2005. In other words, an SR19E90 roof with no deck venting would have the same heat transfer through its roof deck as the subtile vented roof (SR08E90). Hence, the data at peak loading imply that "cool roofing" credits would be obtainable through venting the underside of a stone-coated metal or similarly constructed roof system.

The light-gray shake, the S-mission tile, and the shake covering an existing cedar shake roof have the least amount of heat penetrating the roof deck. The shingle roof allowed about $4482 \mathrm{Btu} / \mathrm{ft}^{2}$ of heat to penetrate the attic floor, whereas only $2218 \mathrm{Btu} / \mathrm{ft}^{2}$ of heat penetrated the attic floor of the light-gray shake with IrBCPs and subtile venting. This in turn leads to a reduction in heat transfer crossing the attic floor (ceiling) of the two attic assemblies. The amount of heat penetrating the attic floor of the assembly with light-gray shake was about $50 \%$ less than that penetrating the attic floor of the assembly with an asphalt shingle roof. 
In addition, all the stone-coated roofs on batten and counter-batten constructions had less heat loss at night to the ambient sky than did the direct-nailed asphalt shingle or direct-nailed stone-coated shake roofs (see blue bars in Fig. 18). This effect is due to the air channel made by the underside of the metal roofs and the batten/counter-batten construction. The ambient air temperature and the bulk air temperature within the vent cavity are almost identical during the twilight hours; there is therefore no thermally induced airflow within the inclined channel. The heat transfer is either conductiondominated or transitional; little venting or airflow movement occurs during the summer nights in July. Typically, when colder, denser air overlays a warmer, less dense sublayer, convective roll waves that enhance heat transfer begin to form. However, for this summer situation the air channel-toambient air temperature gradient is too low for Bénard cell convection because the Rayleigh (Ra) number is about 2000.

\section{Winter Field Exposure}

Cool roofs have received much positive trade press, and some state and federal support for installations where comfort cooling is the dominant building energy load. In mixed climates with both significant heating and cooling loads, the wintertime effect reduces the energy benefit because the desirable roof heat gain in winter is diminished somewhat by the higher solar reflectance of the roof. The Achilles heel of all cool roof systems continues to be the heating penalty that offsets the energy and cost savings associated with the cooling benefit of the reflective roof system. The colder the climate the greater is the penalty, and the trade-off between climate and reflective roofs limits their penetration into predominantly heating load climates. However, field data for the stone-coated metal roofs tested in East Tennessee's climate are showing that the metal's underside venting negates the heating penalty associated with its IrBCP cool roof.

Data for a January week with clear skies, shown in Fig. 19, illustrate the wintertime thermal performance of stone-coated metal roofs compared with that of a dark, heat-absorbing asphalt shingle roof. The ridge vents for these test sections were open, and both attic and deck ventilation were available for this week of January, which had an average daytime ambient air temperature of $36^{\circ} \mathrm{F}$. At solar noon for each of the seven days, the attic assembly with asphalt shingles (SR093E89) absorbed more solar radiation than any of the more reflective stone-coated metal roofs (18 vs $10 \mathrm{Btu} / \mathrm{hr} \cdot \mathrm{ft}^{2}$; see Fig. 19). However, the nighttime losses for the direct-nailed asphalt shingle roof were significantly larger than those for the attics with subtile venting of the shake roofs. The heat loss from the shingle roof at night was roughly twice that escaping from the light-gray or dark-gray shake roofs with batten and counter-batten construction. Painting the underside of the stone-coated metal roof increased the underside thermal emittance from 0.34 to 0.85 and resulted in larger nighttime heat losses from the roof deck. Therefore, the air gap appears to be serving as an insulating layer that forces radiative and convective heat transfer from the roof deck to the metal roof's underside, as compared with the direct conduction path through relatively highly conductive solids in the case of the asphalt shingle roof. From about 8:00 p.m. through about 6:00 a.m. all the stone-coated metal roofs lose less heat to the night sky than does the asphalt shingle roof (Fig. 19). The temperature of the underside of the stonecoated metal is colder at night than that of the shingle, yet the deck temperature for the stone-coated metal roof (with underside venting available but not operative) is warmer than the deck temperature for the direct-nailed shingle roof.

\section{Heating Seasonal Performance: February 2005}

Results integrated over the month of February 2005 show that the underside venting of the stonecoated metal roofs counterbalances the heating penalty associated with cool roofing for the moderate climate of Tennessee (Fig. 20). The asphalt shingle roof gains about $1500 \mathrm{Btu} / \mathrm{ft}^{2}$ per square foot of roof deck during all February days. The painted metal and stone-coated metal roofs nailed directly to 


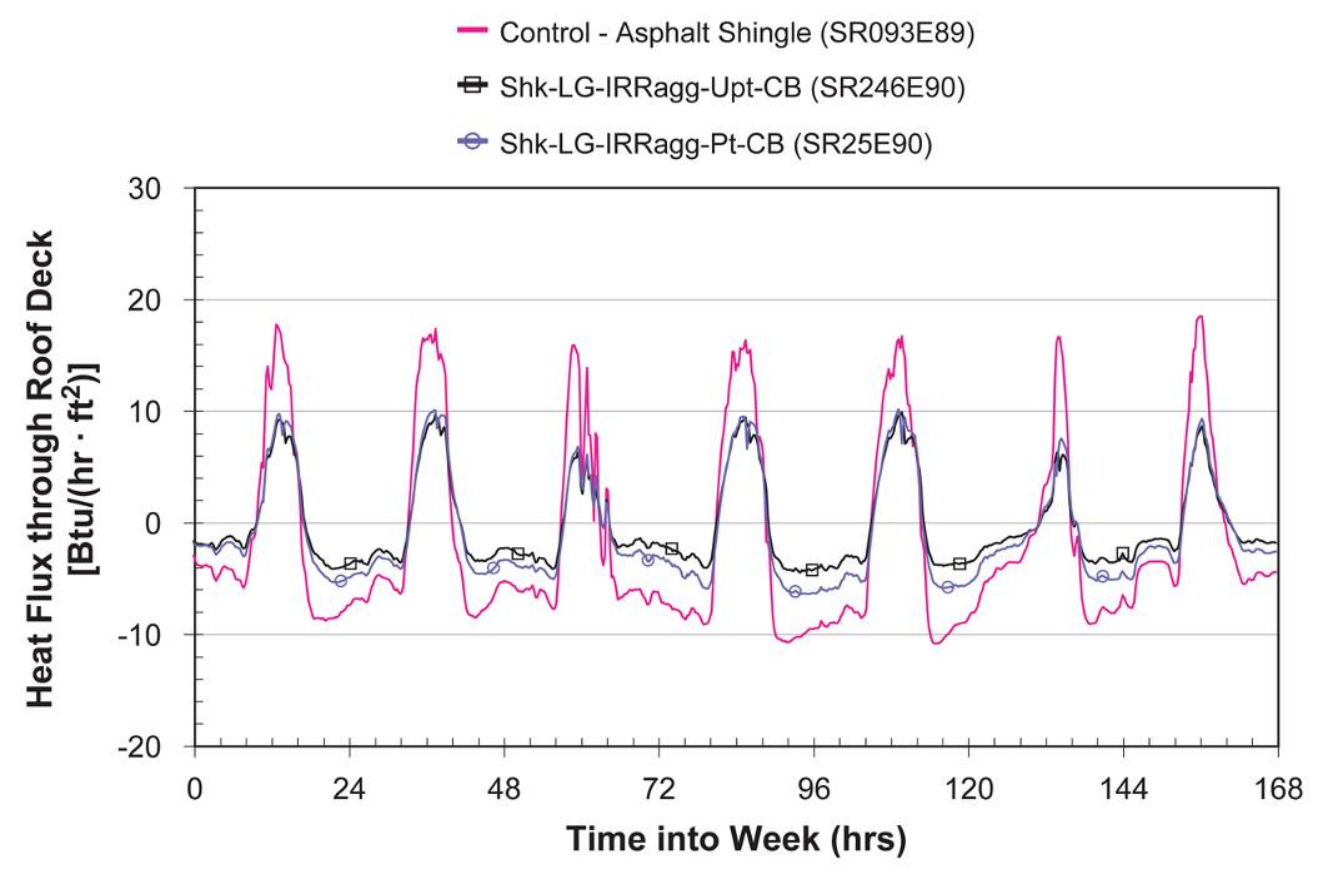

Fig. 19. Heat flow measured through the roof deck for stone-coated metal shake and shingle roofs during January 2005.

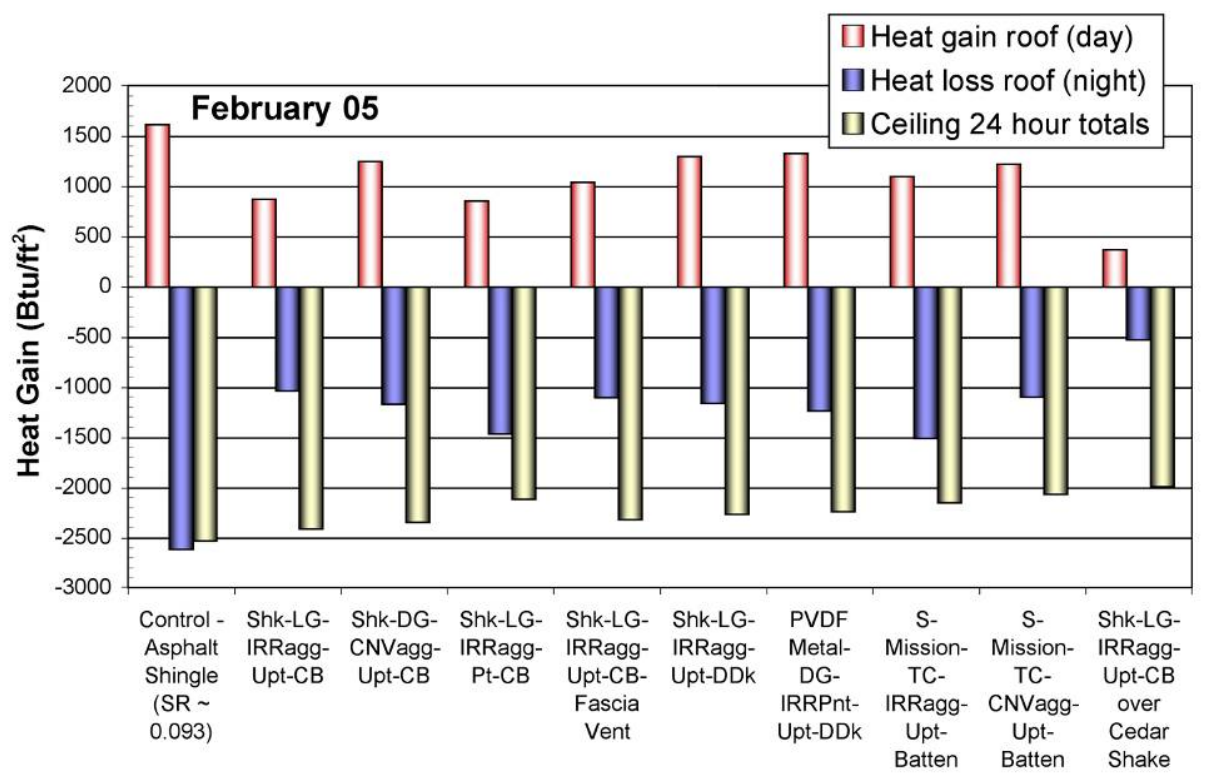

Fig. 20. Integrated heat flow measured through the roof deck for all stone-coated shake and shingle roofs during February 2005.

the deck had the next largest daytime heat gains. The light-gray stone-coated metal roof covering the cedar shake roof had the lowest heat gain simply because of its added thermal resistance due to the cedar wood. However, at night the stone-coated metal roof covering cedar shake had the least heat loss of all tested roof systems. In fact, during the evening hours the insulation air layer on the 
underside of the metal roofs reduced the heat loss from all the stone-coated metal roofs to the point that the heat loss from the ceilings of all roofs was less than the loss from the control shingle (see gold bars, Fig. 20). These data represent a very important finding because they show that stone-coated metal roofs negate the heating penalty associated with a cool roof in Tennessee's moderate climate (3662 $\mathrm{HDD}_{65}$ and $1366 \mathrm{CDD}_{65}$ ).

The improved summer performance coupled with the reduced heat losses during the winter show that infrared reflective metal roofs negate the heating penalty associated with a cool roof. Offset-mounting the infrared reflective stone-coated metal roofs provides a synergistic effect (improved cooling performance and reduced winter heat losses) that the metal roof industry can exploit for marketing its products in that are more predominated by heating loads.

\section{Roof Deck Venting}

The physics of the transfer of heat across offset-mounted stone-coated metal roofs is similar to heat transfer across the inclined air channel formed by roof-mounted solar collectors. Comprehensive reviews of both experimental and theoretical results are available in the literature. Hollands et al. (1976); Arnold, Catton, and Edwards (1976); and, most recently, Brinkworth (2000) studied this situation as applied to flat-plate photovoltaic cladding. All residential roofs are sloped and make an angle, $\theta$, with the horizontal plane that ranges from $9.5^{\circ}$ ( 2 in. of rise per $12 \mathrm{in}$. of run) to $45^{\circ}$ (12 in. of rise per 12 in. of run). During winter exposure, because of the heated space under the roof, a roof deck is warmer than the roof cover. In the inclined air channel the heated surface is positioned below the cooler stone-coated metal roof, much like the solar panel application studied by Hollands et al. (1976). Here, a denser air layer near the metal's underside overlays lighter air adjacent to the roof deck (see $\theta=0$, Fig. 21). Hollands observed that the heat transfer across the air channel can switch from conduction to single-cell convection to Bénard cell convection depending on the strength of a nondimensional parameter called the Rayleigh $\left(\mathrm{Ra}_{\mathrm{H}}\right)^{5}$ number. For Rayleigh numbers less than $1708 / \cos (\theta)$, there is no naturally induced airflow within the cavity, and the heat transfer occurs exclusively by conduction. However, a flow of air occurs if buoyancy forces overcome the resistance imposed by the viscous or frictional forces. As the flow increases due to buoyancy, the heat transfer within the channel can switch to Bénard cell convection, which has hexagonal cells with flow ascending in the center and descending along the sides of the air channel (see $\theta=0$, Fig. 21).

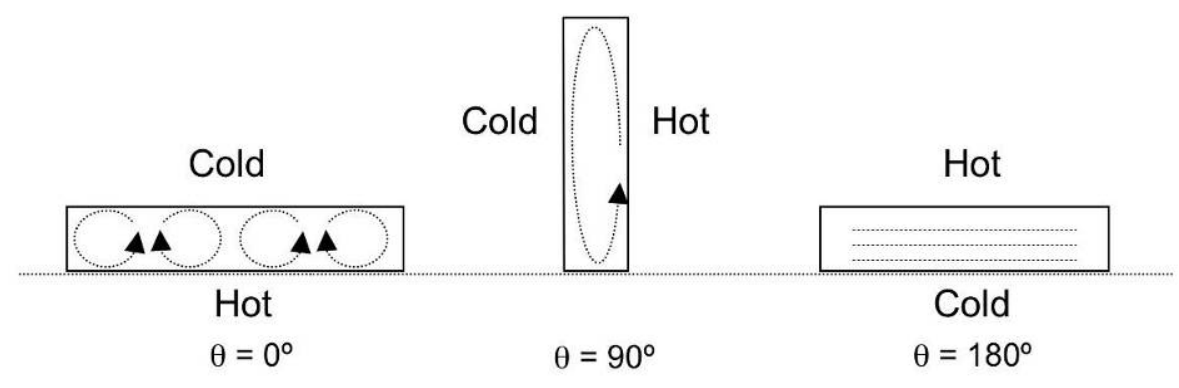

Bénard convection

Conduction dominant

Fig. 21. Heat transfer phenomena on the underside of an offset-mounted roof.

\footnotetext{
${ }^{5}$ The height of the air gap is the characteristic length of the Rayleigh number $\left(\mathrm{Ra}_{\mathrm{H}}\right)$ used here.
} 
Arnold, Catton, and Edwards (1976) observed that the channel's aspect ratio and the slope of the solar panel (or roof for our application) had a major impact on the flow and heat transfer within the air channel. They observed that if the channel was rotated from $\theta=180^{\circ}$ (summer exposure for a roof) all the way to $\theta=0^{\circ}$ (winter exposure), the heat transfer rises to a maximum at $\theta=90^{\circ}$ and then as $\theta$ decreases below $90^{\circ}$ the heat transfer rate first decreases and passes through a local minimum at $\theta^{*}$ (Bejan 1984). However, as $\theta$ decreases below $\theta^{*}$, the heat transfer rate again rises because of the inception of Bénard cell convection. Arnold et al. (1976) also observed that the aspect ratio of the channel changed the critical angle $\theta^{*}$ where the heat transfer across the channel was minimal. This information may be very useful for designing batten and counter-batten roofs to limit ice damming in predominantly cold climates.

During summer exposure, the metal roof is hotter than the roof deck, and Bénard cell convection does not occur within the inclined channel because the lighter air layer is now atop the denser air layer near the roof deck. The air heated by the underside of the stone-coated metal tends to rise, and natural convection begins within a boundary layer formed along the underside of the roof and along the roof deck. Brinkworth (2000) studied this situation as applied to flat-plate photovoltaic cladding; it is this configuration and heat transfer mechanism that is evident in the summer field experiments discussed above for the stone-coated metal and tile roof systems field tested on ESRA.

\section{Thermally Induced Airflow Rates}

An integral technique was used to formulate closed-form solutions for the thermal boundary layer, the velocity profile, and the heat transfer coefficient for the case of natural convection occurring in the inclined channel. Solving the momentum and energy equations for a constant solar flux yielded the following expression for the thermal boundary layers formed in the inclined air channel:

$$
\delta_{\mathrm{T}}=\frac{(288)^{1 / 5}}{\operatorname{Pr}^{2 / 5}}\left[\frac{\{1+5 / 4 \operatorname{Pr}\}^{1 / 5}}{\left\{\frac{g \beta q_{\mathrm{Til}} \operatorname{SIN}(\theta)}{\mathrm{k} \cdot \mathrm{v}^{2}}\right\}^{1 / 5}}\right] x^{1 / 5} .
$$

The velocity profile for the thermally induced air movement in the channel becomes

$$
\mathrm{U}(\mathrm{x}, \mathrm{y})=\mathrm{A}(\mathrm{x})\left\{\eta(1-\eta)^{2}\right\}
$$

where

$$
\begin{array}{ll}
\mathrm{A}(\mathrm{x}) & =\frac{\mathrm{g} \beta\left\{\mathrm{T}_{\text {Roof }}(\mathrm{x})-\mathrm{T}_{\infty}\right\} \delta_{\mathrm{T}} \operatorname{SIN}(\theta)}{4 \mathrm{v}} \\
\eta & =\mathrm{y} / \delta_{\mathrm{T}}
\end{array}
$$

The heat transfer coefficient can be determined by taking the temperature profile within the boundary layer and evaluating its gradient at the underside of the stone-coated metal. Equating the convection to the conduction at the roof's underside yields the expression 


$$
\mathrm{h}_{\mathrm{x}}=\frac{2 \mathrm{k}_{\mathrm{air}}}{\delta_{\mathrm{T}}} .
$$

The expressions in Eqs. (4-6) are useful for estimating approximate values for the bulk velocity and heat transfer coefficient within the air channel. According to these equations, after $14 \mathrm{ft}$ of run from the soffit toward the ridge, the thermal boundary layer has grown to about $0.14 \mathrm{ft}$. Within this boundary layer the maximum air velocity is about $1.8 \mathrm{ft} / \mathrm{s}$, and its average velocity is slightly less than $0.8 \mathrm{ft} / \mathrm{s}$. The local heat transfer coefficient is on the order of $0.23 \mathrm{Btu} / \mathrm{h}$ per $\mathrm{ft}^{2}$ per ${ }^{\circ} \mathrm{F}$ These data help to validate bulk velocities obtained from tracer gas measurements. However, the expressions do not account for the obstructions evident in batten and counter-batten roof constructions.

\section{Numerical Simulations}

Computer simulations for thermally induced airflow and heat transfer across an inclined air channel were conducted for several different constant-temperature wall boundary conditions and several different inclinations with the horizontal plane to better understand the strength of natural convection forces occurring within the heated channel. The channel was modeled with and without obstructions (battens) on the top plate. The bottom and the two side surfaces of the channel were held at $68^{\circ} \mathrm{F}$, and the top surface was fixed at $98^{\circ} \mathrm{F}$ to simulate summer exposure of the test roofs. The aspect ratio of the duct was fixed at 0.01 , and the inclination was $30^{\circ}$ from horizontal ( 5 in. of rise per $12 \mathrm{in}$. of run).

The numerical simulations in Fig. 22 are plotted in terms of isotherms (constant-temperature lines, shown in color) and streamlines (lines of constant velocity). The results depicted in Fig. 22a show that with no obstruction a natural convection flow occurs along the underside of the top plate. An exit jet is seen in line with the duct axis, indicating a velocity flow field within the boundary layer that carries heat away from the roof deck. In Fig. 22b the obstruction (batten) forces the air to move down and around the batten, causing some mixing of air outside the established boundary layer of the smooth surface. The streamlines of constant velocity are observed penetrating almost to the bottom plate because of the obstructions. The typical gap in a batten and counter-batten slate roof is about 0.75 to 2 in., depending on the cross-sectional size of the battens. Recall that according to the boundary layer equation (Eq. 4) after $14 \mathrm{ft}$ from soffit to ridge, the boundary layer had grown to about 1.4 in. Fig. 22b implies that a fully developed flow is established within a shorter distance than occurs in a smooth channel (Fig. 22a).

The result is very similar to the stoking of a fireplace. The air in the chimney initially is cold, and the hot air coming from the fire must develop a boundary layer through the colder chimney air to establish a positive pressure gradient for exhausting the hotter air. The inclined channel with battens forms fully developed flow in a shorter distance (i.e., boundary layers on the top and bottom plates meet in a shorter length of run), and a chimney effect occurs, fueling the removal of heat from the roof deck. Hence, the numerical results help to show qualitatively that the venting occurring on the underside of the roof can be very significant for dissipating heat from the roof deck, making the roof with underside venting cooler than conventional direct-nailed systems.

The numerical results do not take into account the effect of a wind-induced forced-flow component, which may aid or oppose the naturally induced flow. Mixed convection (forced convection driven by wind effects that are accompanied by buoyancy effects) is an additional confounding variable that must be mathematically described before one can predict the heat transfer across the roof deck. The key to the problem is to predict accurately the airflow within the cavity. Once known, the amount of heat penetrating the roof deck and that convected away through the ridge vent can be derived from energy balances. The airflow rate in the inclined channel is very low, and its measurement was attempted with tracer gas techniques. 


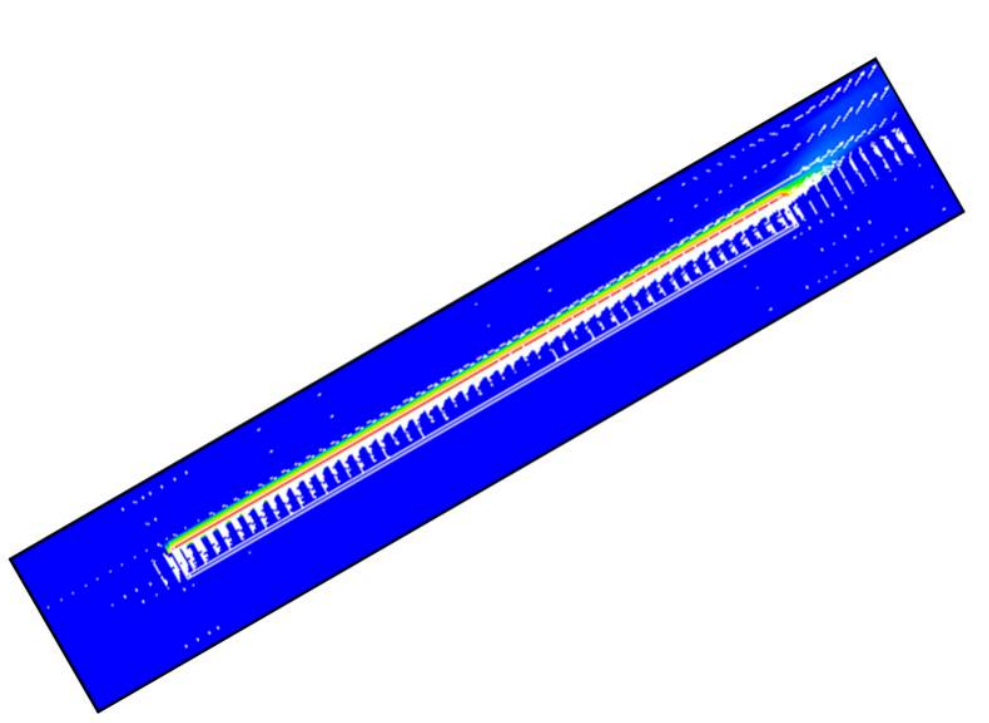

(a) No battens used in simulation

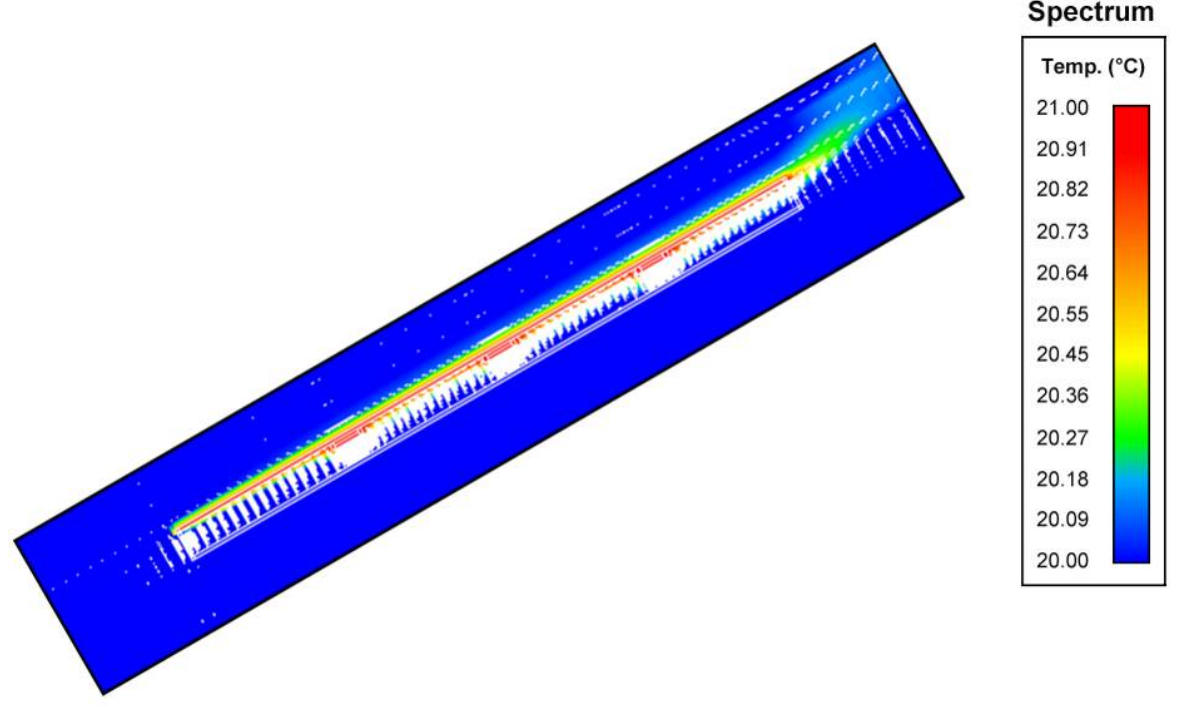

(b) Battens simulated in numerical solution

Fig. 22. Numerical simulations for channel flow with and without battens fastened to the underside of the tile (the top plate). The channel is at an incline of $30^{\circ}$ (a 5-in. rise for every $12 \mathrm{in.} \mathrm{of} \mathrm{run),} \mathrm{and} \mathrm{the} \mathrm{top} \mathrm{plate} \mathrm{is} 30^{\circ} \mathrm{F}$ warmer than the bottom plate.

\section{Airflow Measurements Using Tracer Gas Techniques}

Measurements were made of the airflow underneath the stone-coated shake and S-mission tile roofs as the buoyancy-driven flow traveled from the soffit to the ridge of each roof. We designed a procedure using tracer gas techniques outlined in ASTM E 741 (ASTM 2000) and also by Lagus et al. 
(1988). The procedure required monitoring the decay rate of the tracer gas $\mathrm{CO}_{2}$ with time using the following equation, derived from a continuity balance for the concentration of $\mathrm{CO}_{2}$ :

$$
\dot{\mathrm{V}}_{\text {Air }}=-\frac{\mathrm{VOL}_{\text {channel }}}{\mathrm{t}} \mathrm{LN}\left[\frac{\mathrm{C}(\mathrm{t})-\mathrm{C}_{\infty}}{\mathrm{C}_{\mathrm{i}}-\mathrm{C}_{\infty}}\right] .
$$

Three $\mathrm{CO}_{2}$ monitors were placed inside each attic space, and sampling tubes were inserted into the inclined channel from the underside of the OSB decking. The monitors sampled the gas concentration near the soffit, at the center of the roof, and within $2 \mathrm{ft}$ of the ridge vent. We injected the gas into the vent gap of the soffit and literally saturated the cavity with about 20,000 ppmv of $\mathrm{CO}_{2}$ gas. The polytropic throttling process occurring during the injection of $\mathrm{CO}_{2}$ from a pressurized cylinder (i.e., the gas throttles from about 2000 to $20 \mathrm{psi}$ ) required the gas to be artificially heated to about $110^{\circ} \mathrm{F}$ before being injected into the vent cavity. After a substantial buildup of concentration registered on each monitor (20,000 ppmv of $\mathrm{CO}_{2}$ ), the gas injection was stopped, and the concentration was recorded at timed intervals. Data for the two stone-coated metal shakes and the S-mission tile roofs were collected (Table 7); the calculated airflows ranged from about 10 to $20 \mathrm{cfm}$. The average velocity was about $0.3 \mathrm{ft} / \mathrm{s}$. All measurements were made around solar noon when the roofs were at the highest temperatures and the highest heat flows were penetrating the attic. The light-gray shake with fascia vent does not appear to have increased airflow as compared with the shake with no fascia vent. The uncertainty of measurement for the tracer gas technique was calculated on the basis of a first-order error analysis and is estimated at about $\pm 25 \%$ of measurement. Therefore, the airflows are within the same range for the three roof systems.

Table 7. Airflow rate and bulk velocity measured under the stone-coated metal shake and S-mission roofs using tracer gas techniques

\begin{tabular}{lccc}
\hline & $\begin{array}{c}\text { Light-gray shake on } \\
\text { batten and counter- } \\
\text { batten }\end{array}$ & $\begin{array}{c}\text { Light-gray shake on } \\
\text { batten and counter- } \\
\text { batten (fascia vent) }\end{array}$ & $\begin{array}{c}\text { S-mission tile on } \\
\text { batten }\end{array}$ \\
\hline Volume $\left(\mathrm{V}_{\text {Channel }} \mathrm{in}^{3}\right)^{a}$ & 6673 & 6673 & 11,919 \\
Airflow $(\mathrm{cfm})$ & 16.3 & 17.7 & 9.5 \\
Av. velocity $\left(\mathrm{V}_{\text {air }} \mathrm{ft} / \mathrm{s}\right)$ & 0.26 & 0.28 & 0.27 \\
\hline $\begin{array}{l}\text { a Volume }\left(\mathrm{V}_{\text {Channel }}\right) \\
\text { metering station to another. }\end{array}$ &
\end{tabular}

The tracer gas measurements were used to check the prediction of the underside airflow and heat transfer [Eqs. (4-6)] using internal flow energy balances, experimental data for the underside, and deck temperatures and heat transfer correlations by McAdams (1954) and Nusselt's boundary layer theory. McAdams' correlation is for immersed external free convection flows around a vertical isothermal plate and has the form

$$
\overline{\mathrm{NU}}=\frac{\bar{\hbar} \mathrm{L}}{\mathrm{k}}=0.59\left(\mathrm{Ra}_{\mathrm{L}}\right)^{1 / 4}
$$

The boundary layer correlation for a uniform heat flux has the form

$$
\overline{\mathrm{NU}}=\frac{5}{(11520)^{1 / 5}}\left\{\frac{\operatorname{Pr} \cdot \operatorname{SIN}(\theta)}{4 / 5+\operatorname{Pr}}\right\}^{1 / 5}\left(\mathrm{Ra}^{*}\right)_{\mathrm{L}} .
$$


Equations (8) and (9) were used to back-calculate the mass flow rate of air moving up the inclined air channel. Energy balances for internal duct flow were derived using constant wall and constant heat flux boundary conditions, and the airflow in the enclosed channel was calculated using the measured temperature and heat flow field data for the three stone-coated metal roof systems. Using a constant temperature boundary condition yields the expression

$$
\mathrm{LN}\left[\frac{\mathrm{T}_{\text {Wall }}-\mathrm{T}_{\text {Air out }}}{\mathrm{T}_{\text {Wall }}-\mathrm{T}_{\text {Air in }}}\right]=-\frac{\hbar\{\mathrm{P} \cdot \mathrm{L}\}}{\dot{\mathrm{m}}\left(\mathrm{C}_{\mathrm{P} \text { Air }}\right)},
$$

while the constant flux condition yields the expression

$$
\dot{\mathrm{m}} \cdot \mathrm{C}_{\mathrm{PAir}}\left(\mathrm{T}_{\text {Air out }}-\mathrm{T}_{\text {Air in }}\right)=\mathrm{q}_{\text {solar }}^{\prime \prime}(\mathrm{P} \cdot \mathrm{L})
$$

The constant surface temperature scenario [Eqs. (8) and (10)] yielded volumetric airflow rates of about 24 to $32 \mathrm{cfm}$. The constant heat flux condition [Eqs. (9) and (11)] yielded flow rates of about 40 to $80 \mathrm{cfm}$. This is likely to be high because we used the measured solar irradiance rather than the flux from the underside of the tile (not easily known from field data). These back-calculated airflow values are the same magnitude as of the airflows determined from the tracer gas experiments (see Table 7). 


\section{CONCLUSIONS}

Our tests and data show that the combination of improved solar reflectance afforded by IrBCPs and underside venting make stone-coated metal roofs energy-efficient. These materials can offer excellent energy credits as steep-slope cool roof products. The light-gray stone-coated metal shakes offsetmounted with a batten and counter-batten system reduced the heat transfer penetrating the roof deck by about $45 \%$ compared to the heat penetrating the deck of an attic covered with an asphalt shingle roof. About $15 \%$ of the reduction was due to IrBCPs, while $30 \%$ of the reduction was due to subtile venting. The synergistic effects of solar reflectance and underside venting supported a $70 \%$ reduction in the heat flow penetrating the ceiling into the conditioned space. Subtile venting of the stone-coated metal roofs is just as important as the boost in solar reflectance for reducing the heat gain into the attic and conditioned space.

Heat flows for July 2005 were integrated over the daylight and nighttime hours to show cooling season performance of the various roof systems (Table 8). The fascia vent did not enhance underside venting and shows the least benefit for reducing deck and ceiling heat flows. Painting the underside of a light-gray stone-coated metal roof increases the thermal emittance, which, in turn, degrades the thermal performance of the stone-coated metal roofs. A low thermal emittance provides improved performance by retarding the radiation flow of heat transfer to the deck during this summer month (Table 8). The best performing non-retrofit roofs were the S-mission profile roofs on battens and the light-gray infrared reflective shake roof on battens and counter-battens. Reduction in heat penetrating the ceiling of these prototypes was about $70 \%$ of the heat penetrating through the control shingle roof. Retrofitting a stone-coated shake roof over an existing cedar shake roof proved to be beneficial and resulted in the best thermally performing roof system (Table 8).

Table 8. July 2005 cumulative heat flows through the roof deck and floor of the attic assemblies

\begin{tabular}{|c|c|c|c|c|c|}
\hline \multirow{2}{*}{$\begin{array}{c}\text { Stone-coated and asphalt } \\
\text { shingle roofs }\end{array}$} & \multirow[b]{2}{*}{ SR \& TE } & \multirow{2}{*}{$\begin{array}{l}\text { Roof deck } \\
\text { construction }\end{array}$} & \multicolumn{2}{|c|}{$\begin{array}{l}\text { Roof deck heat flux } \\
(\text { Btu/ft })^{a}\end{array}$} & \multirow{2}{*}{$\begin{array}{c}\begin{array}{c}\text { Attic floor } \\
\text { heat flux } \\
\left(\mathrm{Btu} / \mathrm{ft}^{2}\right)\end{array} \\
24-\text { Hour }\end{array}$} \\
\hline & & & Daylight & Nighttime & \\
\hline $\begin{array}{l}\text { Control: asphalt shingle } \\
(\mathrm{SR} \sim 0.093)\end{array}$ & SR09E89 & Direct-to-deck & 4481.9 & -599.3 & 1926.2 \\
\hline Shk-LG-IRRagg-Upt-CB & SR246E90 & Counter-batten & 2218.0 & -119.6 & 677.3 \\
\hline Shk-DG-CNVagg-Upt-CB & SR08E90 & Counter-batten & 2871.3 & -88.6 & 793.7 \\
\hline Shk-LG-IRRagg-Pt-CB & SR25E90 & Counter-batten & 2406.6 & -123.4 & 1251.5 \\
\hline $\begin{array}{l}\text { Shk-LG-IRRagg-Upt-CB- } \\
\text { Fascia Vent }\end{array}$ & SR244E90 & Counter-batten & 2464.1 & -207.8 & 1461.3 \\
\hline Shk-LG-IRRagg-Upt-DDk & SR25E90 & Direct-to-deck & 2890.3 & -424.2 & 857.6 \\
\hline $\begin{array}{l}\text { PVDF Metal-DG-IRRPnt-Upt- } \\
\text { DDk }\end{array}$ & SR287E90 & Direct-to-deck & 2956.9 & -568.8 & 780.2 \\
\hline $\begin{array}{l}\text { S-mission-TC-IRRagg-Upt- } \\
\text { batten }\end{array}$ & SR257E90 & Batten & 2583.5 & -532.0 & 716.9 \\
\hline $\begin{array}{l}\text { S-mission-TC-CNVagg-Upt- } \\
\text { batten }\end{array}$ & SR15E90 & Batten & 2560.3 & -315.0 & 633.5 \\
\hline $\begin{array}{l}\text { Shk-LG-IRRagg-Upt-CB over } \\
\text { cedar shake }\end{array}$ & SR24E90 & Over cedar shake & 1100.8 & 316.1 & 585.1 \\
\hline
\end{tabular}

${ }^{a}$ Deck heat flux based on floor area of attic assembly. 
During the winter exposure in February 2005 (Table 9), the underside air channel reduced the heat loss from the roof to the point that the heat loss from the ceiling of the stone-coated metal roofs was less than the loss for the asphalt shingle roof. The improved summer performance coupled with the reduced heat losses during the winter show that the infrared reflective metal roofs negate the heating penalty associated with a cool roof in Tennessee's moderate climate (3662 $\mathrm{HDD}_{65}$ and $1366 \mathrm{CDD}_{65}$.). Therefore, offset-mounting stone-coated metal roofs provides the metal roof industry the opportunity to market stone-coated metal roofs in the more predominant heating load climates.

Table 9. February 2005 cumulative heat flows through the roof deck and ceiling of the attic assemblies

\begin{tabular}{|c|c|c|c|c|c|}
\hline \multirow{2}{*}{$\begin{array}{c}\text { Stone-coated and asphalt } \\
\text { shingle roofs }\end{array}$} & \multirow[b]{2}{*}{ SR \& TE } & \multirow{2}{*}{$\begin{array}{l}\text { Roof deck } \\
\text { construction }\end{array}$} & \multicolumn{2}{|c|}{$\begin{array}{l}\text { Roof deck heat flux } \\
(\text { Btu/ft })^{2}\end{array}$} & \multirow{2}{*}{ 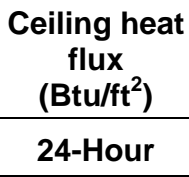 } \\
\hline & & & Daylight & Nighttime & \\
\hline $\begin{array}{l}\text { Control: asphalt shingle } \\
(\mathrm{SR} \sim 0.093)\end{array}$ & SR09E89 & Direct-to-deck & 1609.5 & -2620.5 & -2534.5 \\
\hline Shk-LG-IRRagg-Upt-CB & SR246E90 & Counter-batten & 867.6 & -1040.1 & -2417.4 \\
\hline Shk-DG-CNVagg-Upt-CB & SR08E90 & Counter-batten & 1242.4 & -1173.2 & -2348.3 \\
\hline Shk-LG-IRRagg-Pt-CB & SR25E90 & Counter-batten & 848.8 & -1472.0 & -2118.6 \\
\hline $\begin{array}{l}\text { Shk-LG-IRRagg-Upt-CB- } \\
\text { Fascia Vent }\end{array}$ & SR244E90 & Counter-batten & 1038.1 & -1107.7 & -2325.2 \\
\hline Shk-LG-IRRagg-Upt-DDk & SR25E90 & Direct-to-deck & 1294.0 & -1165.6 & -2268.6 \\
\hline $\begin{array}{l}\text { PVDF Metal-DG-IRRPnt-Upt- } \\
\text { DDk }\end{array}$ & SR287E90 & Direct-to-deck & 1324.9 & -1239.5 & -2242.4 \\
\hline $\begin{array}{l}\text { S-mission-TC-IRRagg-Upt- } \\
\text { batten }\end{array}$ & SR257E90 & Batten & 1091.6 & -1514.7 & -2157.0 \\
\hline $\begin{array}{l}\text { S-mission-TC-CNVagg-Upt- } \\
\text { batten }\end{array}$ & SR15E90 & Batten & 1217.3 & -1102.7 & -2073.3 \\
\hline $\begin{array}{l}\text { Shk-LG-IRRagg-Upt-CB over } \\
\text { cedar shake }\end{array}$ & SR24E90 & Over cedar shake & 366.0 & -532.2 & -1998.5 \\
\hline
\end{tabular}

${ }^{a}$ Deck heat flux based on floor area of attic assembly. 


\section{RECOMMENDATIONS}

It is believed that in the simplest case, with no bulk air velocity, the heat transfer within the roof air channel will be dominated by natural convection, but that the more likely case, given some appreciable value of bulk air velocity, will be mixed convection heat transfer. Understanding the regime of heat transfer within the air channel is essential to accurate modeling of overall heat transmission through the roof assembly. The AtticSim computer tool was validated against the steepslope attic assembly with direct-nailed asphalt shingles. The model predicted well the surface temperature of the shingles, the attic air temperature, and the heat flow penetrating the conditioned space. Efforts are continuing to modify the code for predicting the effects of the airflow occurring on the underside of tile and stone-coated metal roofs. Correlations by McAdams (1954) and Brinkworth (2000) and simple boundary layer theory for a constant solar flux are predicting reasonable heat transfer measures within the inclined air channel. The measures of airflow determined from the tracer gas experiments match well the back-calculated values deduced from the correlations provided by McAdams (1954) and Brinkworth (2000) and simple boundary layer theory correlations. We therefore have good representative airflow measures for subtile venting and are in a good position to implement an algorithm fashioned after the work by Brinkworth (2000) for use in AtticSim to predict thermal performance of roofs with underside venting. 



\section{REFERENCES}

Akbari, H., R. Levinson, and P. Berdahl. 2004. "A Review of Methods for the Manufacture of Residential Roofing Materials.” Report to the California Energy Commission. To be published.

Akbari, H., P. Berdahl, R. Levinson, R. Wiel, A. Desjarlais, W. Miller, N. Jenkins, A. Rosenfeld, and C. Scruton. 2004. "Cool Colored Materials for Roofs,” ACEEE Summer Study on Energy Efficiency in Buildings, Proceedings of American Council for an Energy Efficient Economy, Pacific Grove, CA, August.

Arnold, J. N., I. Catton, and D. K. Edwards. 1976. "Experimental Investigation of Natural Convection in Inclined Rectangular Regions of Differing Aspect Ratios,” Journal of Heat Transfer, February, 67-71.

ASTM (American Society for Testing and Materials). 1996. Designation E903-96: Standard Test Method for Solar Absorption, Reflectance, and Transmittance of Materials Using Integrating Spheres. West Conshohocken, PA: American Society for Testing and Materials.

ASTM. 1997. Designation C 1371-97: Standard Test Method for Determination of Emittance of Materials Near Room Temperature Using Portable Emissometers. West Conshohocken, PA: American Society for Testing and Materials.

ASTM. 2000. Designation E741-00: Standard Test Method for Determining Air Change in a Single Zone by Means of a Tracer Gas Dilution. West Conshohocken, PA: American Society for Testing and Materials.

Beal, D., and S. Chandra. 1995. "The Measured Summer Performance of Tile Roof Systems and Attic Ventilation Strategies in Hot Humid Climates," Proceedings of the Thermal Performance of the Exterior Envelopes of Buildings VI, U.S. DOE/ORNL/BETEC, Clearwater, FL, December 4-8.

Bejan, A. 1984. Convection Heat Transfer. New York: John Wiley \& Sons.

Brinkworth, B. J. 2000. "A Procedure for the Routine Calculation of Laminar Free and Mixed Convection in Inclined Ducts,” International Journal of Heat and Fluid Flow 21: 456-462.

FHA (Federal Housing Administration). 1942. Property Standards and Minimum Construction Requirements for Dwellings. Rev. Washington, DC: Federal Housing Administration.

Hollands, K. G. T., T. E. Unny, G. D. Raithby, and L. Konicek. 1976. "Free Convection Heat Transfer across Inclined Air Layers,” Journal of Heat Transfer, May, 189-193.

Kollie, T. G., F. J. Weaver, and D. L. McElroy. 1990. "Evaluation of a Commercial, Portable, Ambient- Temperature Emissometer,” Review of Scientific Instruments 61:1509-1517.

Lagus, P. L., V. Kluge, P. Woods, and J. Pearson. 1988. “Tracer Gas Testing within the Palo Verde Nuclear Generating Station Unit 3 Auxiliary Building," Proceedings of the 20th NRC/DOE Air Cleaning Conference, Boston, MA, August.

Levinson R., P. Berdahl, and H. Akbari. 2004a. "Solar Spectral Optical Properties of Pigments, Part I: Model for Deriving Scattering and Absorption Coefficients from Transmittance and Reflectance Measurements,” submitted to Solar Energy Materials \& Solar Cells.

_ 2004b. "Solar Spectral Optical Properties of Pigments, Part II: Survey of Common Colorants," submitted to Solar Energy Materials \& Solar Cells.

McAdams, W. H. 1954. Heat Transmission. 3rd ed. New York: McGraw-Hill, Chap. 7. 
Miller, W. A., M-D. Cheng, S. Pfiffner, and N. Byars. 2002. "The Field Performance of HighReflectance Single-Ply Membranes Exposed to Three Years of Weathering in Various U.S. Climates.” Final Report to SPRI, Inc., August.

Miller W. A., K. T. Loyle, A. O. Desjarlais, H. Akbari, R. Levenson, P. Berdahl, S. Kriner, S. Weil, and R. G. Scichili. 2004. "Special IR Reflective Pigments Make a Dark Roof Reflect Almost Like a White Roof,” Thermal Performance of the Exterior Envelopes of Buildings, $I X$, Proceedings of ASHRAE THERM IX, Clearwater, FL, December.

Ozsunar, A., S. Baskaya, and M. Sivrioglu. 2001. "Numerical Analysis of Grashof Number, Reynolds Number and Inclination Effects on Mixed Convection Heat Transfer in Rectangular Enclosures,” International Communications in Heat and Mass Transfer 28, no. 7 (September).

Parker, D. S., J. K. Sonne, and J. R. Sherwin. 2002. "Comparative Evaluation of the Impact of Roofing Systems on Residential Cooling Energy Demand in Florida,” ACEEE Summer Study on Energy Efficiency in Buildings, Proceedings of American Council for an Energy Efficient Economy, Pacific Grove, CA, August.

Petrie, T. W., A. O. Desjarlais, R. H. Robertson, and D. S. Parker. 2000. "Comparison of Techniques for In Situ, Non-damaging Measurement of Solar Reflectance of Low-slope Roof Membranes,” presented at 14th Symposium on Thermophysical Properties, Boulder, CO: National Institute of Standards and Technology. Under review for publication in International Journal of Thermophysics.

Romero, M. I., and R. J. Brenner. 1998. "Instrumentation and Measurement of Airflow and Temperature in Attics Fitted with Ridge and Soffit Vents,” ASHRAE Transactions 104:10741083.

Rose, W. B. 1995. “The History of Attic Ventilation Regulation and Research,” pp. 125-134 in Thermal Performance of the Exterior Envelopes of Buildings, VI, Proceedings of American Society of Heating, Refrigeration and Air-Conditioning Engineers (ASHRAE) conference, Clearwater, FL, December 4-8.

Wilkes, K. E., T. W. Petrie, J. A. Atchley, and P. W. Childs. 2000. "Roof Heating and Cooling Loads in Various Climates for the Range of Solar Reflectance and Infrared Emittance Observed for Weathered Coatings,” pp. 3.361-3.372 in ACEEE Summer Study on Energy Efficiency in Buildings, Proceedings of American Council for an Energy Efficient Economy. Washington, DC: American Council for an Energy Efficient Economy. 